\title{
Trustworthiness and Stability in Same and Different Sex Relationships: Heterosexuals' Attitudes toward Bisexuality
}

Jeneice Shaw

West Virginia University, jlshaw@mail.wvu.edu

Follow this and additional works at: https://researchrepository.wvu.edu/etd

Part of the Counseling Psychology Commons

\section{Recommended Citation}

Shaw, Jeneice, "Trustworthiness and Stability in Same and Different Sex Relationships: Heterosexuals' Attitudes toward Bisexuality" (2019). Graduate Theses, Dissertations, and Problem Reports. 4085.

https://researchrepository.wvu.edu/etd/4085

This Dissertation is protected by copyright and/or related rights. It has been brought to you by the The Research Repository @ WVU with permission from the rights-holder(s). You are free to use this Dissertation in any way that is permitted by the copyright and related rights legislation that applies to your use. For other uses you must obtain permission from the rights-holder(s) directly, unless additional rights are indicated by a Creative Commons license in the record and/ or on the work itself. This Dissertation has been accepted for inclusion in WVU Graduate Theses, Dissertations, and Problem Reports collection by an authorized administrator of The Research Repository @ WVU.

For more information, please contact researchrepository@mail.wvu.edu. 
Trustworthiness and Stability in Same and Different Sex Relationships: Heterosexuals' Attitudes toward Bisexuality

Jeneice Shaw, M.A.

\author{
Dissertation submitted \\ to the College of Education and Human Services \\ at West Virginia University \\ in partial fulfillment of the requirements for the degree of \\ Doctor of Philosophy in \\ Counseling Psychology
}

\author{
Lisa Platt, Ph.D., Chair \\ Monica Leppma, Ph.D., Co-Chair \\ Shane Chaplin, Ph.D. \\ Jeffrey Daniels, Ph.D. \\ Christine Schimmel, Ed.D.
}

Department of Counseling, Rehabilitation Counseling, and Counseling Psychology

Morgantown, West Virginia, 2019

Keywords: Bisexual, Stereotyping, Trustworthiness, Stability

Copyright 2019 Jeneice Shaw 


\begin{abstract}
Trustworthiness and Stability in Same and Different Sex Relationships: Heterosexuals' Attitudes toward Bisexuality
\end{abstract}

Jeneice Shaw

\begin{abstract}
Although bisexuals are reportedly the largest sexual orientation minority group in North America (Copen, Chandra, \& Febo-Vazquez, 2016), there is scant research examining the population without also including lesbian women and gay men. However, according to the American Psychological Association's (2012) Guidelines for Psychological Practice with Lesbian, Gay, and Bisexual Clients, psychologists should endeavor to understand the unique experiences of the bisexual population. Bisexual individuals face different stereotypes, conflict within the LGB community, and different life experiences related to other sexual orientations (Rust, 2000). Two unique stereotypes applied to the bisexual community are that bisexuality is an unstable sexual orientation (Bostwick \& Hequembourg, 2014) and that bisexual individuals are untrustworthy (Israel \& Mohr, 2004). Currently, there is no research exploring differences in perceptions of these stereotypes between male and female bisexual individuals and scant research examining perceptions of bisexual individuals in same or different gender relationships. When research has been completed in these areas, it has tended to focus on bisexual men and women separately or on differences in perceptions depending upon the heterosexual person's gender. The current study explored 558 heterosexual participants' perceptions of bisexuality and used sexual orientation, gender, and type of relationship as independent variables and trustworthiness and stability as dependent variables. Results suggest there are no differences in perception of stability between bisexual men and women or same or different gender relationships. Additionally, no differences in trustworthiness between bisexual men and women and heterosexual and bisexual individuals were found. However, participants did perceive bisexual individuals in same gender relationships to be more trustworthy than those in different gender relationships. Possible explanations for these results, limitations of the study, and future directions are explored.
\end{abstract}




\section{DEDICATION}

So many people in my life were instrumental in the completion of this dissertation, but only one had to listen to every worry, doubt, or irrational stress. I would like to dedicate this dissertation to my husband, Nathan, for being the person to provide me constant and unwavering support and encouragement throughout this entire process.

I would also like to dedicate this work to the two most hard working and resilient people I know, my parents, Via and Mike. Completing this dissertation took perseverance and patience, and my parents modeled that to me better than any other person.

Finally, I would like to dedicate this dissertation to those in the bisexual community who have felt unseen, unheard, and misunderstood. Our identity is valid and our experiences are important. This dissertation is evidence that perceptions are changing. 


\section{ACKNOWLEDGEMENTS}

I would like to thank my dissertation chair, Dr. Lisa Platt for her help and support in this endeavor. I cannot overestimate my gratitude for your patience, guidance, availability, and support throughout this entire process. Thank you for taking me on as one of your first dissertation students and for walking with me on this journey. I would also like to thank my committee members for answering my questions, showing their support, and taking the time out of their lives to be a part of my committee.

Also, thank you to the College of Education and Human Services for awarding funds toward this dissertation with the Berlin B. Chapman Graduate Student Award. These funds helped garner the necessary sample size quickly and easily.

I would also like to thank Chelsea Latorre for her help with proofreading and formatting this final document. You are so appreciated, and I cannot wait to return the favor on your dissertation.

Thank you to my friends who provided support throughout this entire process, especially to Olivia Scott who was with me every step of the way and Brittany Shannon who was a great example on how to do a great dissertation.

Finally, I would like to thank Vicki Railing for always keeping me up to date with requirements and deadlines and for always being wonderfully supportive. I would never have made it through this program without you. 


\section{TABLE OF CONTENTS}

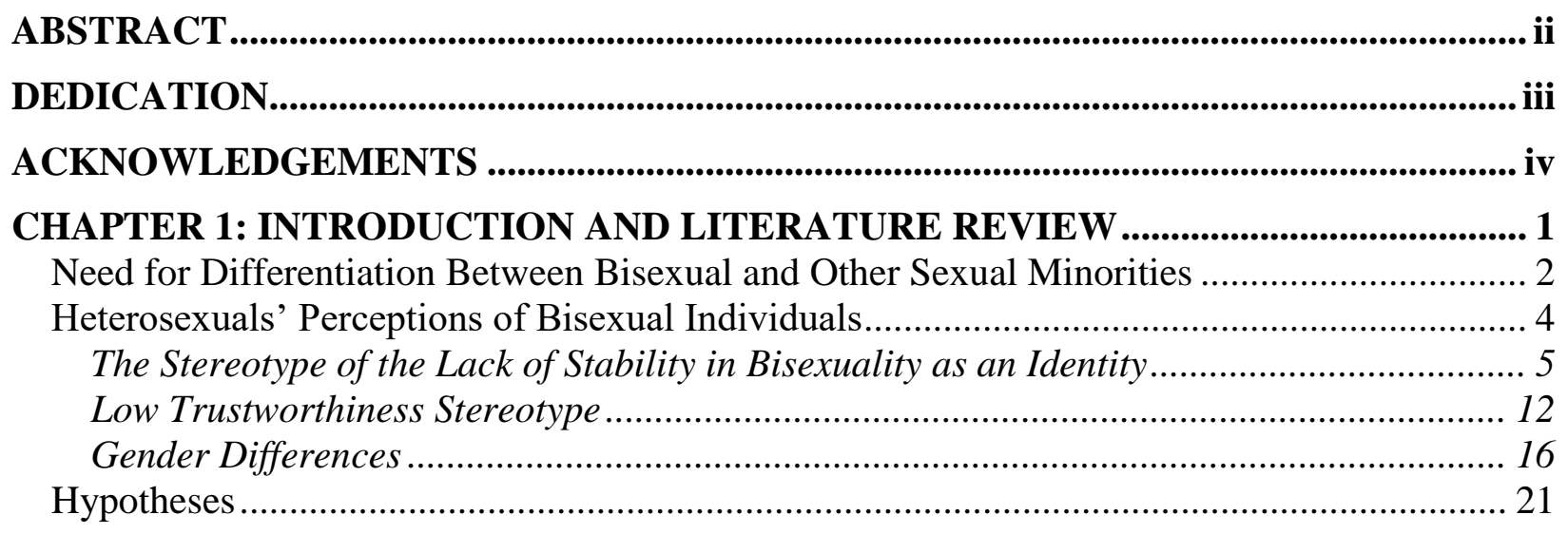

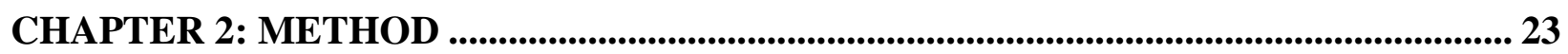

Research Questions and Hypotheses .................................................................................... 23

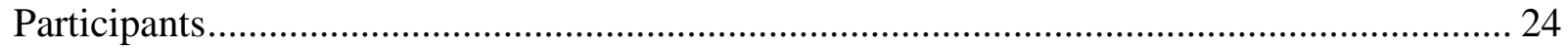

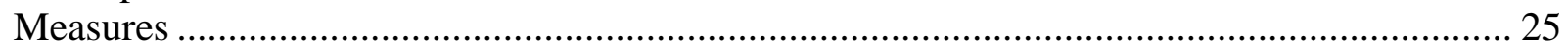

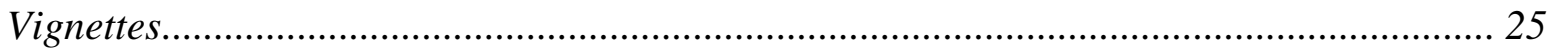

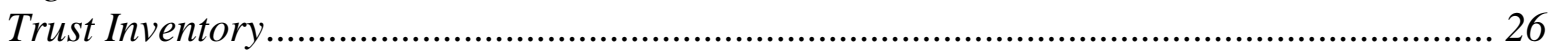

Attitudes Regarding Bisexuality Scale-Female Version .................................................... 27

Attitudes Regarding Bisexuality Scale-Male Version ..................................................... 28

Demographic Questionnaire..................................................................................... 30

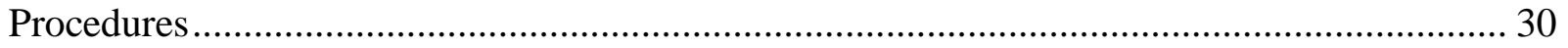

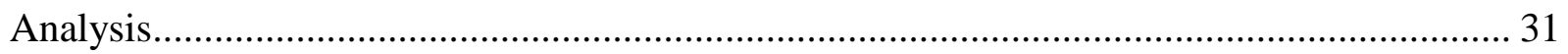

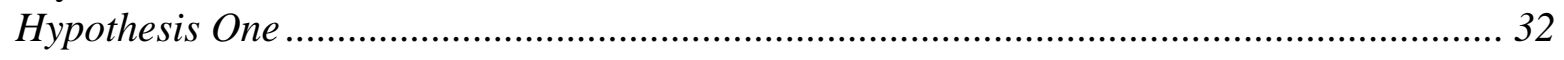

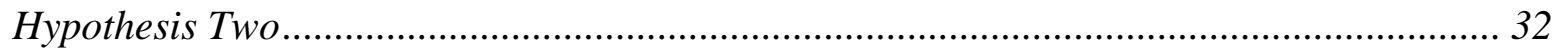

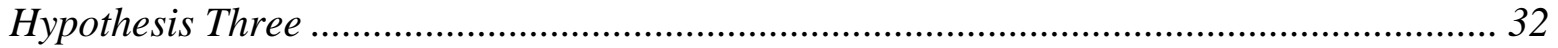

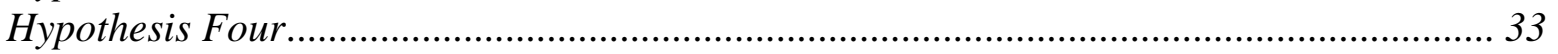

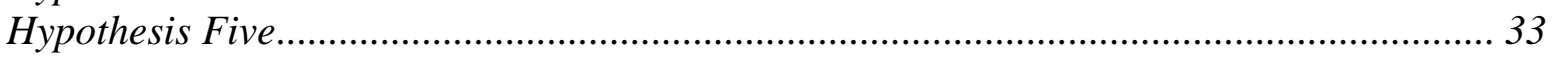

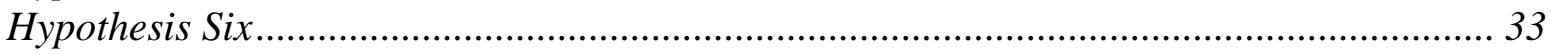

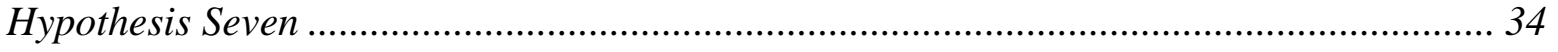

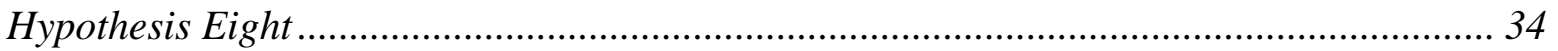

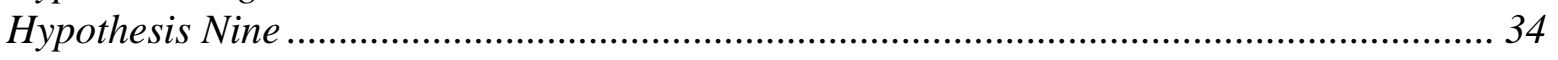

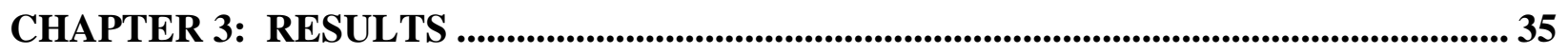

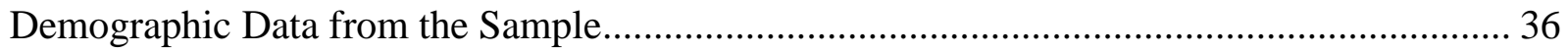

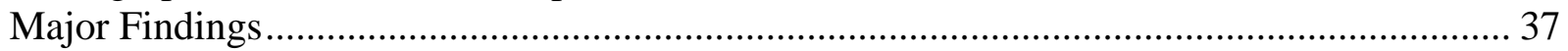

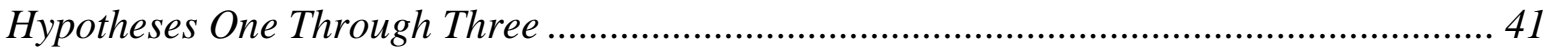

Hypotheses Four Through Six ………….................................................................... 42

Additional Analyses ................................................................................................. 44

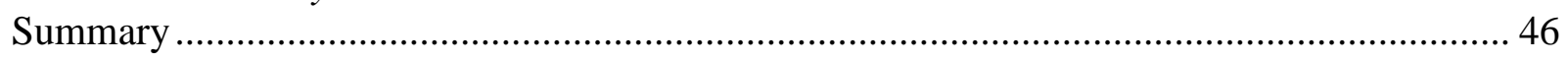

CHAPTER 4: SUMMARY AND DISCUSSION ....................................................................... 47

Discussion of Stability in Bisexual Relationships (Hypotheses 1-3) ...................................... 47

Discussion of Trustworthiness in Bisexual Relationships (Hypotheses 4-6) ........................... 49

Discussion of Trustworthiness Overall (Hypotheses 7-9) ....................................................... 53 


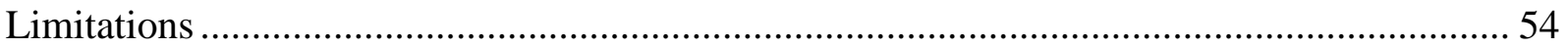

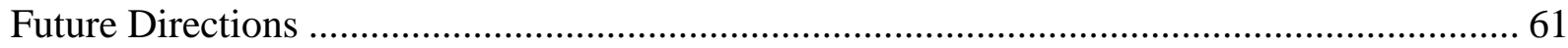

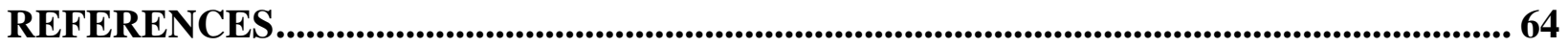

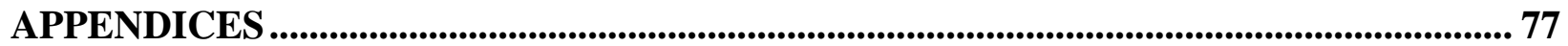

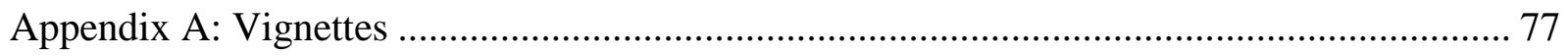

Appendix B: Manipulation Check …………………….................................................. 79

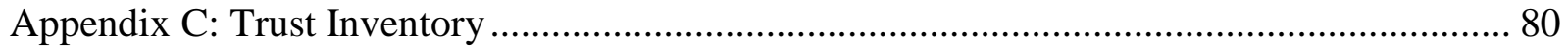

Appendix D: Attitudes Regarding Bisexuality Scale-Female Version, Stability Subscale ...... 81

Appendix E: Attitudes Regarding Bisexuality Scale-Male Version, Stability Subscale ........... 82

Appendix F: Demographics Questionnaire ........................................................................... 83

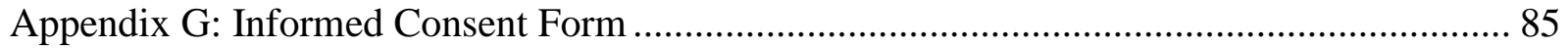

Appendix H: Debriefing Form...................................................................................... 86

Appendix I: IRB Approval........................................................................................ 87

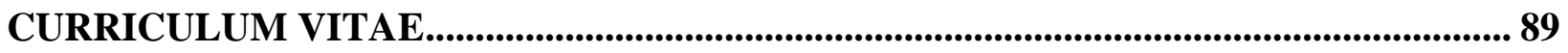




\section{CHAPTER 1: INTRODUCTION AND LITERATURE REVIEW}

Bisexual people, defined as those who have romantic, emotional, and/or sexual attractions to both men and women (American Psychological Association [APA], 2008) or others regardless of gender (Bowes-Catton, 2007), are the largest sexual minority group in North America (Copen, Chandra, \& Febo-Vazquez, 2016). According to the APA's (2012) Guidelines for Psychological Practice with Lesbian, Gay, and Bisexual Clients, psychologists should endeavor to understand the unique experiences of the bisexual population. This dissertation is an experimental study to examine how bisexual individuals and their relationships are perceived by heterosexual individuals. Specifically, this dissertation will explore differences in how bisexual relationships are perceived by heterosexual individuals in terms of trustworthiness and stability depending upon the gender of the bisexual individual in each scenario and whether they are in a same or different-gender relationship. This literature review will explore research on heterosexual individuals' perceptions of bisexual individuals, specifically the stereotypes that bisexual individuals are not trustworthy and that the identity of bisexual is unstable.

It is important to note that language and vocabulary in the LGBTQ+ (lesbian, gay, bisexual, transgender, queer/questioning, plus) community is constantly shifting and evolving (Cormier, 2019; Parents and Friends of Lesbians and Gays [PFLAG], 2019). Bisexuality is sometimes confused with pansexuality as they both describe sexual orientations in which there is attraction to more than one gender (Galupo, Ramirez, Pulice-Farrow, 2017). However,

pansexuality often refers to an attraction to all expressions of gender identity (Sorrel, 2018) whereas bisexuality often refers to an attraction to two or more genders (Bowes-Catton, 2007). However, because of the constant evolution in LGBTQ+ terminology (Cormier, 2019; PFLAG, 2019) and political and personal implications related to sexual identity (Sorrel, 2018), it is best 
practice and empowering to allow each individual to self-identify instead of placing labels upon them based on strict definitions (Wagaman, 2016). For the sake of an operational definition, in the current study, bisexuality refers to "an individual who experiences attraction to more than one gender or whose attractions are based on characteristics other than gender" (Bowes-Catton \& Hayfield, 2015, p. 42).

\section{Need for Differentiation Between Bisexual and Other Sexual Minorities}

According to Meyer's (2003) minority stress model, those within sexual minority populations experience additional life stressors not faced by their heterosexual peers due to heterosexism (i.e.,, the assumption that heterosexual is the normal and expected sexual orientation). Heterosexism can manifest in different ways including rejection, harassment, discrimination (Szymanski, 2006), internalized heterosexism, and sexual orientation concealment (Szymanski, Kashubeck-West, \& Meyer, 2008). Possibly as a result, in comparison to heterosexuals, those in sexual minority communities tend to have higher rates of psychological distress (Cochran, Sullivan, \& Mays, 2003; Mays \& Cochran, 2001; Woodford, Kulick, Sinco, \& Hong, 2014) and greater health and healthcare disparities (Ard \& Makadon, 2012).

Collectively, members of the LGBTQ+ community struggle with different issues than their heterosexual peers. However, there are also differences between groups within the LGBTQ+ community. Unfortunately, in the literature bisexual experiences are often grouped into the broad category of LGBTQ+. Although there is a rationale for this grouping (it is the popular acronym for all those identifying as a sexual and/or gender minority), in research it leads to erasure, meaning a removal or disregard, of the unique experiences of the specific individuals within this spectrum. Historically, much of the research looking at bisexual men and women failed to differentiate them from gay men and lesbian women, often describing the populations as 
"gay/bisexual men" and "lesbian/bisexual women." However, bisexual individuals have specific and unique cultural and social experiences and face different stereotypes, prejudice both in and outside of the LGBTQ+ community, disconnect from the LGBTQ+ community, and different life experiences related to other sexual orientations (Balsam \& Mohr, 2007; Bostwick \& Hequembourg, 2014; Brewster \& Moradi, 2010; Israel \& Mohr, 2004; Rust, 1995; Rust, 2000).

Due to a lack of research on solely bisexual individuals, there is little knowledge on the specific struggles faced by bisexual people, particularly in relationships. Stereotypes faced by bisexual people can lead to added difficulty disclosing their sexual orientation (Mohr, Jackson, \& Sheets, 2017; Pistella, Salvati, Ioverno, Laghi, \& Baiocco, 2016) and can lead to internalized biphobia (Burke \& LaFrance, 2018). In addition to this, bisexual youth are less likely to report acceptance from family and friends, have less knowledge of supportive resources, are less happy, have more substance use problems, feel less likely to have a sense of community, and are less likely to come out than their gay and lesbian peers (Andre et al., 2014). Finally, adult bisexuals are more likely to experience intimate partner violence and sexual assault than their gay and lesbian peers (Walters, Chen, \& Breiding, 2013).

Because continued research and knowledge on any cultural group is necessary for cultural competence (Clay, 2010), it is important for counseling psychologists to understand the stereotypes, prejudices, and unique challenges faced by those who identify as bisexual. Additionally, this research is important for counseling psychologists because it can help illuminate any biases that psychologists working with bisexual clients may unknowingly hold and help prevent any unwittingly harmful behaviors, microaggressions, or imposition of values on clients from occurring in therapy (Meyers, Morse, \& Wheeler, 2015). Finally, by understanding the impact that stereotyping may have on a bisexual client's experiences in 
relationships (Feinstein, Dyar, Bhatia, Latack, \& Davila, 2014; Feinstein, Dyar, Bhatia, Latack, \& Davila, 2016), connection to or disconnect from the LGBTQ+ community (Balsam \& Mohr, 2007; Rust, 1995), internalized biphobia (Burke \& LaFrance, 2018), and overall general emotional (Cochran et al., 2003; Mays \& Cochran, 2001; Woodford et al., 2014) and physical (Ard \& Makadon, 2012) wellbeing, counseling psychologists can better understand and conceptualize their bisexual clients' presenting concerns. This knowledge of stereotyping and improved conceptualization can also lead to more effective culturally competent treatment planning and outcomes (Substance Abuse and Mental Health Services Administration [SAMHSA], 2014).

A necessary step to ensure culturally competent treatment of bisexual individuals is to study their experiences separately from lesbian women and gay men. This study will attempt, through the use of formalized assessments, to investigate perceptions of bisexual people. This study will provide empirical data to aid clinicians in understanding the unique struggles faced by bisexual people.

\section{Heterosexuals' Perceptions of Bisexual Individuals}

Hequembourg and Brallier (2009) reported that bisexual individuals may be vulnerable to similar stereotyping, discrimination, and exclusion faced by the LG community as well as unique challenges not faced by the LG community. For example, past research has suggested that it is considered more unacceptable to be a bisexual man or woman than a lesbian woman or gay man (Eliason \& Raheim, 1996). In research by Eliason (1997), only a small minority of survey respondents considered bisexuals to be "very acceptable" (12\% men; 14\% women). Eliason (1997) also reported that among a pool of 229 heterosexuals, $61 \%$ and $50 \%$ considered bisexual 
men and women to be "very unacceptable" or "somewhat unacceptable," respectively. These were higher percentages in these categories than gay men (43\%), and lesbian women (38\%).

Negative perceptions of bisexuals are likely created in part due to negative stereotypes about bisexuals. These stereotypes include the idea that bisexuals are carriers of AIDS to the heterosexual community, unable to commit (to both relationships and identities), better at "passing" as heterosexual, accessing "the best of both worlds" (i.e.,, LG community and heterosexual community), choosing partners based on social privileges, indecisive, confused, incapable of being monogamous, having more active sex lives than all other sexual orientation groups, and that bisexuality is a transitional stage to either a hetero or homosexual identity (Rust, 2000). Additionally, because bisexual individuals participate in same-gender romantic and sexual behaviors, they are also subject to many of the same stereotypes and discriminatory behavior faced by lesbian women and gay men. Ochs (1990) described this phenomenon, "We don't lose only half our children in custody battles. When homophobia hits, we don't get just half fired from our jobs...We, too, get discriminated against because we are gay” (p. 2).

Gay men, lesbian women, and heterosexual individuals report hesitancy or refusal to begin a relationship with a bisexual person (Feinstein et al., 2014; Feinstein et al., 2016) and bisexuals have reported exclusion from the LGTBQ+ community (Bostwick \& Hequembourg, 2014; Ross, Dobinson, \& Eady, 2010). Additionally, heterosexuals report believing that bisexuality is an immoral and unacceptable sexual orientation, which certainly would impact how they treat those in the bisexual community (Mohr \& Rochlen, 1999).

\section{The Stereotype of the Lack of Stability in Bisexuality as an Identity}

Before disclosing one's sexual orientation, beginning a relationship, and owning the identity of bisexual in a heterosexist culture, one of the first struggles for many is to come to 
terms with the idea of being bisexual. Bisexuality is often considered to be an "in between" sexual orientation, even by those in the sexual minority community, leading to the idea that it is not a stable identity and relationships with bisexual people are unstable (Bostwick \& Hequembourg, 2014; Hequembourg \& Brallier, 2009). The legitimacy of the bisexual label is often called into question and is treated as inauthentic (Israel \& Mohr, 2004), leading many to wonder if they can even legitimately claim it as a label. Even in academic literature studying bisexuality as a stable sexual orientation, the possible fluidity of bisexuality that is present in all sexual orientations is emphasized over its static identity (Richardsfink, 2014). However, bisexuality is no more fluid than any other type of sexual orientation (Barker et al. 2012).

Bisexuality is also portrayed as an unstable identity in popular culture. It is often shown as a stage of transition on the way to identifying as gay or lesbian or as a temporary phase (Barker \& Landridge, 2008). Bisexuals are often considered to be confused, in denial, experimenting, or currently in transition from heterosexuality to homosexuality or vice versa, rendering their identity as illegitimate (Brewster \& Moradi, 2010; Eliason, 1997, 2001; Israel \& Mohr, 2004; Klein, 1993; Mohr \& Rochlen, 1999; Mulick \& Wright, 2002).

This perspective of instability likely originated with, or at least was given credence by, Sigmund Freud's (1905/1963) writings and opinions on bisexuality in adults. Freud considered bisexuality an immature sexual orientation - something that was not yet developed. Specifically, in Freud's (1905/1963) view, bisexuality was a polymorphous sexuality, meaning that bisexual individuals can gain sexual pleasure outside of "normal" sexual behaviors. By considering only heterosexual sexual activities as "normal," those participating in same-gender sexual behaviors are "othered," meaning that their activities are outside of the cultural default: heterosexuality. But, in addition to the idea of bisexuality being abnormal, Freud (1905/1963) also noted that 
polymorphous sexuality is normal for children from infancy until around age five. Therefore, bisexuality in Freud's (1905/1963) view was not only abnormal, it should have been dealt with developmentally in the earliest stages of life. This encourages the idea that bisexuality is an immature sexual orientation and that, because it is not fully developed, it is not a legitimate sexual orientation for a mature adult.

Those who endorse the belief that bisexuality is a transitional sexual orientation may believe this for several reasons. According to Eliason (2001), some individuals consider bisexual people as too afraid to come out and disclose a gay or lesbian identity and face the full social and relational consequences of that identity. Similarly, others consider bisexuality as a way to maintain the social privileges of being heterosexual while still being a member of a sexual minority community (Rust, 1993). While some individuals may indeed experience their sexual orientation in a fluid manner, many others find bisexuality is a stable, consistent identity, which makes this a harmful stereotype.

In a qualitative study by Alaire and Gaudet (2013), participants described bisexuality as a temporary phase and expressed both explicitly and implicitly that only monosexual sexual orientations (i.e., heterosexual, gay, lesbian) were legitimate, long-term identities. Some discussed bisexuals as being confused and alternating between male and female partners to help make up their minds. They believed that at some point, bisexuals would realize which gender they prefer, which would indicate their "true" sexual orientation.

In an experimental study, Flanders and Hatfield (2014) found that heterosexual, bisexual, and gay/lesbian college students struggled to label someone as bisexual if they had only had one experience or only fantasies with someone of the same gender. Although Flanders and Hatfield's (2014) quantitative results suggested that participants considered the subject of the 
vignette to be bisexual (76.8\%), the open-ended responses provided more detail on participants' thought processes behind their responses. For the female vignette subject, participants hesitated to label her as not heterosexual because she had only had one experience with the same gender. Instead, the participants described her as "bicurious" (e.g., "I believe that you can be totally heterosexual, while being bicurious" [Flanders \& Hatflied, 2014, p. 241].). Male vignette subjects were labeled as gay or bicurious in many of the open-ended examples provided by Flanders and Hatfield (2014). For example, a participant began her answer by labeling the subject as bisexual, but then suggesting that he is possibly gay: "Bisexual, but technically there's not enough information to conclude that. He could have been in self-denial the entire [time] he has been with women, and only now accepting and allowing himself to be who is [sic] truly is, homosexual" (Flanders \& Hatfield, 2014, p. 242). It seemed that for many participants, one same-gender experience for a woman was not enough for her to not be heterosexual, but one same-gender experience for a man was enough for him to be considered gay. In the examples provided by Flanders and Hatfield (2014), participants rarely labeled the subjects as bisexual.

Because sexual orientation is often viewed as dichotomous, bisexuality is sometimes seen as an illegitimate sexual orientation - even for those who do not identify as heterosexual (Israel $\&$ Mohr, 2004). Feeling attracted to more than one gender makes it difficult for bisexual individuals to be classified in binary, dichotomous terms. To correct for the "messiness" of a bisexual identity, people sometimes perceive the identity of bisexual as an equal split in attraction to men and women (Israel \& Mohr, 2004). If there is a preference toward one gender, that determines whether the individual in question is considered to be gay/lesbian or heterosexual (Alaire \& Gaudet, 2013). This means bisexual individuals are faced with a behavioral standard that is impossible to achieve. They are expected to have both male and female partners, in equal 
numbers, to validate their bisexual identity. In reality, most bisexual individuals do not experience an equal attraction to men and women (Galupo et al., 2017; Poynter, 2016). By not experiencing equal levels of attraction toward the same and other gender, many bisexual individuals shatter the idea that attraction is easily contained. As a result, people who endorse this belief may consider a person with a more uneven split to actually be gay or lesbian.

Often, attraction is disregarded and bisexual individuals in committed, monogamous relationships are often disregarded or considered to not be bisexual because they are in a relationship. They are often labeled gay/lesbian or heterosexual, rendering the identity of bisexual as invisible (Boyer \& Galupo, 2015). On the other hand, individuals who participate in bisexual behaviors by having partners and attraction to both genders are also called into question, as some only consider bisexuality as "real" if a person has felt or expressed romantic love toward both genders (Alaire \& Gaudet, 2013).

As mentioned previously, when bisexuals participate in both same and different-gender romantic and sexual relationships, they are often perceived to be either heterosexual or gay/lesbian, depending on the gender of their partner. Women who participate in same-gender romantic or sexual behaviors are often considered to just be performing for men's sexual gratification and are actually heterosexual, regardless of their actual sexual identification (Esterline \& Galupo, 2013; Rupp \& Taylor, 2010). For example, in an experimental study by Lanutti and Denes (2012), women who kissed other women were more likely to be perceived as heterosexual than bisexual or lesbian. Additionally, male bisexuals are more likely to be considered to be gay than bisexual based on same-gender sexual behaviors (Alaire \& Gaudet, 2013; Anderson \& Adams, 2011) and bisexual women are more likely to be considered heterosexual than bisexual, even in cases of same-gender sexual behavior (Alaire \& Gaudet, 
2013). Even some individuals who report having sexual behaviors and desires for the same and different genders choose not to identify as bisexual as they do not consider bisexuality to be an authentic sexual orientation (Alaire \& Gaudet, 2013). The belief that same-gender romantic and sexual behaviors are performative to please others, not the actual participants, strengthens the belief that bisexuality is not a real sexual orientation (Boyer \& Galupo, 2015).

Bisexual participants in Bostwick and Hequembourg's (2014) study reported regularly having their sexual identity dismissed as not legitimate. These microaggressions were labeled denial/dismissiveness and involved stories of bisexual women being told that their identity was incorrect or even not real. Bostwick and Hequembourg (2014) explored how this denial is possibly related to the dichotomous nature of our culture related to sexual orientation. In other words, one has to choose what gender they are attracted to as both is not an acceptable answer. This may be because the majority of romantic relationships are monogamous, meaning the relationship is only between two people. It may be hard for those not identifying as bisexual to understand how one could be in a monogamous relationship and still feel attraction toward someone of a different gender than their partner. Some may not understand how someone can claim attraction toward more than one gender while only being romantically involved with one gender at a time. However, a similar scenario often occurs in monosexual relationships when a partner feels attraction for someone outside of the relationship. One does not have to act on this attraction or betray their relationship to make the attraction real. Similarly, bisexual people do not have to act on attractions with both genders to prove that their identity is real.

Additionally, forcing a bisexual person's sexual identity to fit the dichotomous framework of hetero- or homosexual is disempowering. Bostwick and Hequembourg (2014) explained, "The knower [bisexual individual] is explicitly wronged by others who (re)work their 
conception of the woman's identity into a monosexual framework, irrespective of her own testimony" (p. 7). In Bostwick and Hequembourg's (2014) work, some women reported pressure from partners to change their identity to "match" with the relationship that they were in at that time. Bostwick and Hequembourg (2014) labeled this as a pressure to change. They explained that this microaggression reinforces the idea that a bisexual label is a transitional identity - not stable enough to be real on its own. Some women reported being pressured by their partners to change how they identify even after having a discussion about their sexual orientation and receiving the initial feedback that the identity of bisexual was acceptable. Others reported being pressured by friends identifying as lesbians and were warned that no lesbian would ever want to date a bisexual woman.

By not participating in the idea that sexual orientation is dichotomous, bisexuality is sometimes considered to be complex and confusing. Because the dominant culture tends to misunderstand and be confused by bisexuality, the onus of that confusion is often placed on the bisexual population. For example, in a study by Jurgens, Schwitzer, and Middleton (2004), a theme that arose from heterosexual college students' perceptions of gay men and lesbian women was that they considered bisexual individuals to be "confused." Participants shared the idea that bisexuals are gay men and lesbian women who have just become confused. This misunderstanding and perceived complexity of bisexuality was labeled "unintelligibility of bisexuality" by Bostwick and Hequembourg (2014). Participants described this as people very plainly being confused about the identity of bisexual. The unintelligibility microaggression did not involve participants' identities being ignored or treated as if they do not exist, but instead being treated as illogical, confusing, and unable to be understood. Comments such as "I just 
don't understand" were common. Also, Zivony and Lobel (2014) reported that bisexual men are viewed as more indecisive and confused in comparison to all non-bisexual men.

Finally, although many different individuals do not believe that bisexuality is a legitimate and stable sexual orientation, some characteristics are related to this belief. Those who endorse conservative beliefs including low egalitarian beliefs, high social dominance orientation, political conservatism, and discreteness beliefs, tend to associate bisexuality with low stability (Feinstein et al., 2016). As a result of this perception of lower stability in bisexual individuals, those with conservative beliefs are less willing to date bisexuals (Feinstein et al., 2016).

\section{Low Trustworthiness Stereotype}

Low trustworthiness, a major stereotype bisexual people face, is the idea that because there is attraction to more than one gender, bisexuals must act on those attractions and cannot be faithful in a relationship (Israel \& Mohr, 2004). In prior research, bisexual men and women both reported being judged by heterosexuals as being untrustworthy as well as promiscuous (Hequembourg \& Brallier, 2009). Bisexuals are often considered to not only be untrustworthy romantic partners (Israel \& Mohr, 2004; Mohr \& Rochlen, 1999; Spalding \& Peplau, 1997) but also untrustworthy friends (Gustavson, 2009; Klesse, 2005; McLean, 2004). They are also considered to not be loyal to their partners (Israel \& Mohr, 2004). Many believe that the quality of a romantic relationship with a bisexual partner will be low and that bisexual partners will be unfaithful in the relationship, resulting in the spread of sexually transmitted infections (STI's) to their partners (Alaire \& Gaudet, 2013; Klesse, 2005; McLean, 2004; Spalding \& Peplau, 1997).

Spalding and Peplau (1997) found that heterosexual college students in their sample considered bisexual people in relationships less likely to be monogamous, more likely to be unfaithful to their partners, and more likely to carry and give their partners an STI than 
heterosexual individuals in a relationship. Other researchers have found similar results in which bisexual individuals are considered promiscuous, carry STI's, and incapable of maintaining a monogamous relationship (Brewster \& Moradi, 2010; Eliason, 1997; Eliason, 2001; Fahs, 2009; Gustavson, 2009; Herek, 2002; Israel \& Mohr, 2004; Lanutti \& Denes, 2012; McLean, 2004; Mint, 2004; Mohr \& Rochlen, 1999).

In other research, heterosexual women reported worry that if they were to have a bisexual male partner that he would cheat on them or leave them for a man (Armstrong \& Reissing, 2014). It is also often assumed that bisexuals cannot be trusted in a relationship as they cannot resist sexual temptation (Alaire \& Gaudet, 2013) and do not want to have long-term romantic commitments as this would restrict them to monogamy (George, 1993; Mclean, 2004). Thus, they are often not considered to be suitable partners for dating or marriage (Breno \& Galupo, 2008; Spalding \& Peplau, 1997).

Past research has suggested that both heterosexual and gay/lesbian individuals are hesitant to become romantically or sexually involved with a bisexual partner, even if they report being attracted to them (Eliason, 1997). In experimental research by Armstrong and Reissing (2014), heterosexual women and men reported more negative attitudes toward bisexual partners as the commitment level (i.e.,, casual sex, dating, committed relationship) of each relationship they were presented with increased. Participants reported feeling fear of their partner's possible infidelity and experiencing jealousy toward their hypothetical partner's male and female friends. Breno and Galupo (2008) reported that participants completing a marriage-matching task rarely paired bisexuals with heterosexuals, gay men, or lesbians. They concluded that this suggests bisexuals are considered only acceptable to be paired with other bisexuals in romantic relationships. 
Zivony and Lobel (2014) also found in an experimental study that bisexual men are considered less trustworthy when compared to all non-bisexual men. Additionally, Zivony and Lobel (2014) found that a bisexual man dating a woman is considered less trustworthy and less likely to maintain a long-term relationship in comparison to a bisexual man dating another man. On the other hand, a bisexual man dating another man is considered more likely to have had many previous romantic relationships when compared to a bisexual man dating a woman (Zivony \& Lobel, 2014).

Zivony and Lobel (2014) addressed the perceived difference heterosexual people saw between bisexual men dating women and men. They noted the most consistent and harmful stereotypes found in their results concerned bisexual men dating women. Zivony and Lobel (2014) used integrated threat theory (Stephan \& Stephan, 2000) to explain their results. According to integrated threat theory, prejudice stems from a perceived threat to ingroup members. Zivony and Lobel (2014) suggested that bisexual men may be considered to be a threat to heterosexual women due to other stereotypes facing bisexuals. Specifically, because bisexual men can have relationships with other men, they are perceived as more likely to pass an STI to a heterosexual woman and to reject monogamous relationships than a heterosexual man would, leading to the heterosexual woman experiencing some type of physical or emotional damage (Israel \& Mohr, 2004; Zivony \& Lobel, 2014). Symbolically, bisexual men may appear to reject relationship values that heterosexual people believe they themselves hold.

Bisexual individuals also tend to be portrayed as oversexualized which likely contributes to the stereotype of untrustworthiness as well. Spalding and Peplau's (1997) research with heterosexual college students found that participants thought people with bisexual partners were more sexually satisfied than people with heterosexual partners. However, the same participants 
believed that lesbian women and gay men in relationships with bisexual partners would be less likely to be sexually satisfied than if they were with a partner with their sexual orientation. This suggests that heterosexual people consider those who identify as sexual minorities to be "better" at sex than heterosexual individuals. In terms of bisexual individuals, this may be due to the idea that they have more "practice" with both men and women.

The oversexualization of bisexuals (also termed hypersexuality) was identified as a category of microaggression against bisexual women by Bostwick and Hequembourg (2014). In this qualitative study, participants reported that they were treated differently in both platonic and romantic relationships by those who believed bisexuals are hypersexual. Some participants shared that when they disclosed a bisexual identity in a dating situation, the other partner decided they no longer wanted to date them. Qualitative research by Feinstein et al. (2014) also reported similar findings: gay, lesbian, and heterosexual individuals all reported that they were less likely to engage in a relationship with a bisexual partner than with a partner sharing their own sexual orientation. In Bostwick and Hequembourg's (2014) study, many participants reported only dating other bisexual people to avoid this situation. The authors speculated that the hesitancy to date the bisexual group participants relates to the stereotype that bisexual individuals are hypersexual and will begin a sexual relationship with anybody. Participants also reported comments from friends who they believed meant well, but also reinforced the hypersexual stereotype. Some comments reported by the participants were "So would you have sex with anyone then?" (Bostwick \& Hequembourg, 2014, p. 11) and "Okay, so that means you want a three-way, right?” (Bostwick \& Hequembourg, 2014, p.11).

Also, as reflected in Blumstein and Schwartz's (1974) work with the radical lesbian feminist movement, if one does not fit into a clearly defined category (i.e.,, interested in the same 
gender or interested in the other gender), it can lead to uncertainty and suspicion about a bisexual person's political leanings. If a bisexual person can just "hide" in their identity and "pass" as heterosexual, what stops them from abandoning the sexual minority community and leaving that identity behind? Being able to abandon the sexual minority identity by "hiding" in a heterosexual relationship may impact the amount of trust another person identifying as a sexual minority feels they can place in a bisexual person.

\section{Gender Differences}

Prior research has also shown gender to be an important variable in heterosexual perceptions of bisexual individuals. Generally, attitudes toward bisexual men are typically more negative than attitudes toward bisexual women (Eliason, 2001; Mohr \& Rochlen, 1999; Steffans \& Wagner, 2004; Yost \& Thomas, 2012), particularly among heterosexual men (Herek, 2000). Heterosexual women tend to have more tolerance toward male bisexuality than do heterosexual men. However, they still consider gay men and lesbians to be more acceptable than bisexuals, male or female (Israel \& Mohr, 2004). Interestingly, heterosexual men often rate bisexual women more positively than bisexual men, gay men, and lesbian women (Yost \& Thomas, 2012).

Although heterosexual men tend to be more accepting of female bisexuality than their female counterparts, this is partially explained by the male eroticization of women's samegender sexuality (Yost \& Thomas, 2012), which is often depicted in media and pornography to cater to the male demographic (Jenefsky \& Miller, 1998). According to Fahs (2009), there has been increased pressure in recent years on women to perform bisexuality to accommodate men's sexual fantasies. 
Women's bisexuality is often not taken seriously, possibly as a result of performative bisexuality. In a qualitative study by Hequembourg and Braillier (2009), lesbian and bisexual women participating in a focus group shared experiences in which they felt their relationships were dismissed by heterosexual men, describing several events in which heterosexual men aggressively flirted with them even after being told they were in a same-gender relationship. Unsurprisingly then, some believe that female bisexuality is a strategy for women, particularly college-aged women, to reaffirm their own heterosexuality by gaining the attention of men (Alaire \& Gaudet, 2013). Diamond (2005) noted that the media typically portrays women in sexual relationships with other women as heterosexual women trying bisexuality, enjoying their experience with another woman, but deciding that same-gender sexual contact was the "wrong" type of enjoyment for them, ultimately returning to heterosexuality. She argued that the most acceptable form of female-female sexuality is one that is played for the male gaze, reassuring men that these women are still sexually available to them. Diamond's (2005) conclusion is not implausible as public displays of affection between women are considered more acceptable if both of the women appear to be feminine and stereotypically heterosexual (Alaire \& Gaudet, 2013). Fahs (2009) takes this argument a step further stating, "For women, the rules are clear: either choose a man for a sexual partner, or choose a woman with a man's approval” (p. 447).

Performative bisexuality in women has become normalized, and Alaire and Gaudet (2013) found that some people consider it to be almost a "rite of passage" for young women. Participants described it as something to make young women appear "cool" and sexually open, while still maintaining their heterosexuality and any want for male attention. However, while being considered "cool," women are simultaneously considered to be more promiscuous if they engage in public displays of affection with a woman than with a man (Lannutti \& Denes, 2012). 
Additionally, although generally female bisexuals are viewed more positively than male bisexuals, when a bisexual woman is suspected of performing or faking bisexuality for male attention, they are viewed more negatively than men who are accused of faking bisexuality for fear of coming out as gay (Alaire \& Gaudet, 2013). It is important to notice that in both scenarios, an individual simply being bisexual was not an option.

Male bisexuality is less socially accepted than female bisexuality (Alaire \& Gaudet, 2013). Even those who consider female bisexuality to be acceptable, consider male bisexuality to be "bizarre" (Alaire \& Gaudet, 2013). Male bisexuals have also been considered to be either nonexistent or neurotic (Klein, 1993).

Bisexual men are also often considered to be in transition to a gay identity and this explanation is used to explain male bisexuality far more than female bisexuality (Alaire \& Gaudet, 2013). Anderson (2008) discussed the "one time rule" for sexual orientation in men, describing the phenomenon that men may have a history of heterosexual relationships, but that one same-gender experience disregards that history and labels them as gay. Men who participate in same-gender behaviors are automatically considered to be gay, with no true attraction to women (Anderson, 2005). Additionally, Flanders and Hatfield's (2014) quantitative analysis suggested that the gender of the person in question impacts how others perceive their sexual orientation and its stability. The authors noted that women tended to be seen as having more flexible sexual orientations and desires than men. Their results suggested that men were perceived as significantly more likely to be gay than heterosexual than were women who expressed same-gender interest.

Additionally, heterosexual men and women view bisexual stability differently. Heterosexual men consider bisexuality overall to be a less stable sexual orientation than 
heterosexual women do (Mohr \& Rochlen, 1999). However, according to Armstrong and Reissing (2014), it is significantly more important to heterosexual women than to heterosexual men to know if their opposite-gender partners are bisexual. Heterosexual women report worry that if they had a male bisexual partner, that he would "become" gay in the future, that they would be unable to fulfill their partner's sexual needs, and that their partner would cheat on them. The extent to which heterosexuals believe bisexuality is a stable sexual orientation tends to hold more importance for heterosexual women (Feinstein et al., 2016).

There are also gender differences in terms of how bisexual individuals are viewed as carriers of STI's, particularly HIV (Eliason, 2001). Specifically, there is the fear that closeted bisexual men are more likely to be unfaithful to their wives with men carrying HIV, thus bringing the infection back home to their wives (Spalding \& Peplau, 1997). In addition to this, some in the lesbian community believe that engaging in sexual activity with a bisexual woman creates the risk of bringing HIV into the lesbian community. Many lesbians consider their community to be safe from HIV because they do not have romantic relationships with men (Ochs, 1996). However, HIV can infect lesbian women via avenues other than having relationships with women who have had sexual contact with men in the past.

Perceptions of bisexuality are evolving and some research has suggested that the public, particularly younger individuals, are beginning to accept bisexuality as a legitimate and nonstigmatized sexual orientation (Anderson \& Adams, 2011). However, many negative perceptions are still endorsed and bisexuality is often forgotten and the dichotomous view of sexuality relied upon, even among those who believe bisexuality to be a legitimate sexual identity (Alaire \& Gaudet, 2013; Anderson \& Adams, 2011). 
In conclusion, bisexual individuals face several stereotypes, two of the most prominent among them being that they are untrustworthy romantic partners and that their identity is not stable. Bisexuals are considered less likely to maintain a monogamous relationship, more likely to be unfaithful in a romantic relationship, and more likely to spread STI's to their partners (Spalding \& Peplau, 1997). Additionally, they are often considered to be either heterosexual, gay/lesbian, or "bicurious," but rarely bisexual regardless of their self-identification, past romantic/sexual history, or attractions (Flanders \& Hatfield, 2014). Differences in how bisexual men and women are perceived (Eliason, 2001) in addition to differences in how heterosexual men and women perceive bisexuals (Israel \& Mohr, 2004) have been explored.

This body of literature suggests that instability and a lack of trustworthiness are major stereotypes faced by those in the bisexual community. Additionally, differences in perceptions of bisexual men and women have been reported. However, more research using controlled experimental methodology is still needed. This dissertation will add to past literature by adding an updated quantitative measurement of heterosexuals' perceptions of bisexuals' trustworthiness and stability. Also, differences between the trustworthiness and stability ratings depending on gender and gender of the romantic partner will be assessed. To date, this has not yet been explored in past research. This dissertation is an experimental study to examine how bisexual individuals and their relationships are perceived by heterosexual individuals. Specifically, this dissertation will explore differences in how bisexual relationships are perceived by heterosexual individuals in terms of trustworthiness and stability depending upon the gender of the bisexual individual in each scenario, and whether they are in a same or different-gender relationship. 


\section{Hypotheses}

The present experimental study will use the following three independent variables: sexual orientation, gender, and type of relationship with trustworthiness and stability as the dependent variables. Nine hypotheses are proposed:

Using a 2 x 2 design with the independent variables of type of relationship and gender and a dependent variable of stability, with only the bisexual conditions:

1. After excluding heterosexual conditions, there will be a significant main effect for type of relationship, in that same gender relationships will be rated as less stable than different gender relationships.

2. After excluding heterosexual conditions, there will be a main effect for gender in that bisexual women will be rated as less stable than bisexual men.

3. After excluding heterosexual conditions, there will be an interaction effect for type of relationship and gender indicating that bisexual women in same gender relationships will be rated the lowest in stability.

Using a $2 \times 2$ design with the independent variables of type of relationship and gender a dependent variable of trustworthiness, with only the bisexual conditions:

4. After excluding heterosexual conditions, there will be a main effect for type of relationships in that bisexual individuals in different gender relationships will be rated as less trustworthy than bisexual individuals in same gender relationships.

5. After excluding heterosexual conditions, there will be a main effect for gender in that bisexual men will be rated as less trustworthy than bisexual women. 
6. After excluding heterosexual conditions, there will be an interaction effect for type of relationship and gender such that bisexual men in different gender relationships will be rated as the least trustworthy.

Using a 2 x 2 design with the independent variables of gender and sexual orientation and a dependent variable of trustworthiness:

7. There will be a main effect for gender in that women will be rated as less trustworthy than men.

8. There will be a main effect for sexual orientation in that bisexual individuals will be rated as less trustworthy than heterosexual individuals.

9. There will be an interaction effect for gender and sexual orientation such that bisexual women will be rated as the least trustworthy overall. 


\section{CHAPTER 2: METHOD \\ Research Questions and Hypotheses}

There are three research questions under investigation in this study. In this study I seek to investigate if bisexual people are considered by heterosexual people to be less stable and less trustworthy in relationships than heterosexual people. Additionally, do heterosexual people perceive bisexual people in same-gender relationships differently than bisexual people in different-gender relationships in terms of trustworthiness and stability? Finally, is perception of trustworthiness and stability impacted by the gender of the partners in the relationship? The independent variables in this study are gender, sexual orientation, and type of relationship, each with two levels (i.e.,, male or female, heterosexual or bisexual, same-gender or different-gender). The dependent variables in the study are trustworthiness and stability. Nine hypotheses are proposed:

Using a 2 x 2 design with the independent variables of type of relationship and gender and a dependent variable of stability, with only the bisexual conditions:

1. After excluding heterosexual conditions, there will be a significant main effect for type of relationship, in that same gender relationships will be rated as less stable than different gender relationships.

2. After excluding heterosexual conditions, there will be a main effect for gender in that bisexual women will be rated as less stable than bisexual men.

3. After excluding heterosexual conditions, there will be an interaction effect for type of relationship and gender indicating that bisexual women in same gender relationships will be rated the lowest in stability. 
Using a $2 \times 2$ design with the independent variables of type of relationship and gender a dependent variable of trustworthiness, with only the bisexual conditions:

4. After excluding heterosexual conditions, there will be a main effect for type of relationships in that bisexual individuals in different gender relationships will be rated as less trustworthy than bisexual individuals in same gender relationships.

5. After excluding heterosexual conditions, there will be a main effect for gender in that bisexual men will be rated as less trustworthy than bisexual women.

6. After excluding heterosexual conditions, there will be an interaction effect for type of relationship and gender such that bisexual men in different gender relationships will be rated as the least trustworthy.

Using a $2 \times 2$ design with the independent variables of gender and sexual orientation and a dependent variable of trustworthiness:

7. There will be a main effect for gender in that women will be rated as less trustworthy than men.

8. There will be a main effect for sexual orientation in that bisexual individuals will be rated as less trustworthy than heterosexual individuals.

9. There will be an interaction effect for gender and sexual orientation such that bisexual women will be rated as the least trustworthy overall.

\section{Participants}

Participants for this study were heterosexual adults obtained on Amazon Mechanical Turk (MTurk). They were offered twenty-five cents to complete the study, which is standard compensation in MTurk. It was anticipated that the participants would more often be White (Huff \& Tingley, 2015), women, and those reporting a higher education level and lower income 
rate than the general population (Paolacci, Chandler, \& Ipeirotis, 2010). Also according to research completed by Paolacci et al. (2010), MTurk users are majority women and have an average age of around 36. Because this study explored perceptions of bisexual people held by the dominant group (heterosexuals), only heterosexual participants were considered in this study. Five-hundred fifty-eight participants were included in the analysis. A post hoc power analysis using G*Power (Faul, Erdfelder, Lang, \& Buchner, 2007) indicated a 99\% chance of detecting a moderate effect size (.025) as significant between groups at the 5\% level with 558 participants. Of these, $58.9 \%$ were men $(n=329), 40.7 \%$ were women $(n=227), .2 \%$ were trans men $(n=1)$, and were $.2 \%$ genderqueer/gender non-conforming $(n=1)$. They ranged in age from 18 to 76 years with an average age of $34.6(S D=11.06)$. The majority of participants identified as White/Caucasian $(59.1 \% ; n=330)$, with $24 \%$ identifying as Asian $(n=134), 6.4 \%$ identifying as Black/African-American $(n=36), 6.1 \%$ identifying as Latino/a $(n=34), 2.9 \%$ identifying as American Indian/Alaskan Native $(n=16), 1.1 \%$ identifying with two or more races $(n=6), .2 \%$ identifying as Native Hawaiian/Pacific Islander $(n=1)$, and .2\% with another race/ethnicity that was not listed $(n=1)$. In terms of marital statuses, $45.5 \%$ of participants reported being married currently $(n=254)$. The typical highest level of education completed by participants was a Bachelor's degree $(47.7 \% ; n=266)$. Participants were randomly assigned to the six study conditions with 95 participants in condition one, 92 in condition two, 92 in condition three, 99 in condition four, 85 in condition five, and 95 in condition six.

\section{Measures}

\section{Vignettes}

To manipulate the three independent variables of the study, participants read one of six vignettes describing a bisexual or heterosexual man or woman in a same or different-gender 
relationship (See Appendix A). The vignettes vary across the three independent variables (i.e.,, gender, type of relationship, and sexual orientation), each with two levels (i.e.,, male or female, same or different-gender, and heterosexual or bisexual). In the vignette, a person in a two year relationship begins a new job. Soon after beginning the job the relationship ends and the person begins a relationship with someone in their office. The vignette directly notes the sexual orientation of the person under question and that they believe the relationship will last. Each vignette is identical aside from the names, genders, and sexual orientations of the characters. The vignettes were created by the author and were pilot tested on a small group of individuals unaware of what the study was investigating to determine if the manipulation had the desired impact and to confirm wording and readability. As a manipulation check in both the pilot and

full study, participants answered two questions to determine if they understood who the vignette was about and what that person's sexual orientation was (See Appendix B).

\section{Trust Inventory}

The Trust Inventory (TI; Dunn \& Schweitzer, 2005) (See Appendix C) assesses expectations of trustworthiness and intentions to trust another person and was adapted from Johnson-George and Swap's (1982) Specific Interpersonal Trust Scale. The TI was chosen for the current study because, although there are several scales measuring trust of specific individuals (i.e.,, Assessment of Trust Orientation; Couch, Adams, \& Jones, 1996) or systems (i.e.,, Occupational Trust Inventory; Cummings \& Bromily, 1996) in a person's life, the TI is currently the only scale created to measure trust in a hypothetical situation with a hypothetical person. The TI includes 10 items and is rated using a 7-point Likert Scale ranging from 1 (not at all likely) to 7 (very likely). Examples of items are: "If [person from vignette] laughed unexpectedly at something I did or said, I would know s/he was not being unkind." and "[person 
from vignette] would never intentionally misrepresent my point of view to others." It is scored by finding the mean of the responses, with lower scores indicating less perceived trustworthiness. Trustworthiness as measured by the TI will serve as one of the dependent variables in the study. In Dunn and Schweitzer's (2005) original study, the TI was used in several conditions to measure expectations of trustworthiness of hypothetical coworkers based on a primed emotion (e.g.,, anger, joy, etc.). The internal consistency reliability of the TI in these conditions range from .85 to .89. Gino and Schweitzer (2008), Lount (2010), and Vaughn, Harkness, and Clark (2010) have also used Dunn and Schweitzer's (2005) scale and reported that the items are highly correlated $(\alpha=.95, \alpha=.85$, and $\alpha=.91$ respectively). In the original scale by Johnson-George and Swap (1982), the scale was found to exhibit evidence of discriminant validity. Other studies using the adapted survey found excellent internal consistency reliability (Chronbach's $\alpha=.98$ ) (Condon, Ritchie, \& Igou, 2015). In the current study, the TI had high internal consistency as well in both the female and male versions, with Chronbach's alphas of .93 and .94 respectively.

\section{Attitudes Regarding Bisexuality Scale-Female Version}

The Attitudes Regarding Bisexuality Scale-Female Version stability subscale (ARBS-F; Mohr \& Rochlen, 1999) (See Appendix D) measures if bisexuality in women is perceived as a "legitimate, stable sexual orientation" (p. 356) and if bisexual women are considered to be able of "forming committed romantic relationships" (p. 356). The ARBS-F stability subscale includes 6 items. In Mohr and Rochlen's (1999) original study, a factor analysis on an initial pool of 80 items found two meaningful factors assessing the degree to which bisexuality is viewed as a moral and tolerable sexual orientation (tolerance, 6 items) and as a legitimate and stable sexual orientation (stability, 6 items). Each item is rated using a 5-point Likert Scale 
ranging from 1 (strongly disagree) to 5 (strongly agree). Examples of questions include "Most women who identify as bisexual have not yet discovered their true sexual orientation" and "Most women who call themselves bisexual are temporarily experimenting with their sexuality." The ARBS-F stability subscale is scored by reverse scoring as needed and then calculating the mean of the responses, with higher means reflecting a more positive attitude toward bisexual women.

The ARBS-F stability subscale had moderate to high internal consistency reliability in gay, lesbian, and heterosexual samples. In heterosexual samples, the stability subscale was strongly related to attitudes toward lesbians and gay men, frequency of religious attendance, political ideology, and contact with lesbian, gay, and bisexual individuals. Among lesbians and gay men, the subscale was correlated with prior contact with bisexual people, desired contact with bisexual people, contact with heterosexuals, and sexual orientation (Mohr \& Rochlen, 1999). Other studies using the ARBS-F also reported high internal consistency of the stability subscale $(\alpha=.89$, Dyar, Lytle, London, \& Levy, 2017; $\alpha=.91$, Feinstein et al., 2016; $\alpha=$ Tebbe $\&$ Moradi, 2012; $\alpha=.89$, Worthington, Dillon, Becker-Schutte, 2005). In the current study, the stability subscale also had high reliability (6 items; $\alpha=.87$ ).

\section{Attitudes Regarding Bisexuality Scale-Male Version}

The Attitudes Regarding Bisexuality Scale-Male Version stability subscale (ARBS-M;

Mohr \& Rochlen, 1999) (See Appendix E) measures if bisexuality in men is perceived as a "legitimate, stable sexual orientation" (p. 356) and if bisexual men are considered to be able of "forming committed romantic relationships" (p. 356). Mohr and Rochlen (1999) developed the ARBS-F and ARBS-M to be identical aside from the gender of the bisexual person in question. To do so, the researchers eliminated any items that loaded less than .40 on only one factor 
(stability or tolerance). After doing so, any items without a pair were also eliminated so that only pairs of parallel items that met the .40 loading requirement remained.

The ARBS-M stability subscale includes 6 items. A factor analysis on an initial pool of 80 items found two meaningful factors assessing the degree to which bisexuality is viewed as a moral and tolerable sexual orientation (tolerance, 6 items) and as a legitimate and stable sexual orientation (stability, 6 items). Each item is rated using 5-point Likert Scale ranging from 1 (strongly disagree) to 5 (strongly agree). Example questions include "Just like homosexuality and heterosexuality, bisexuality is a stable sexual orientation for men" and "Most men who identify as bisexual have not yet discovered their true sexual orientation." The ARBS-M stability subscale is scored by reverse scoring as needed and then calculating the mean of the responses, with higher means reflecting a more positive attitude toward bisexual men.

The ARBS-M evidenced moderate-to-high internal consistency reliability in both lesbian and gay samples and heterosexual samples. Stability and the ARBS-M tolerance subscale were significantly correlated for the ARBS-M $(r=.62, p<.001)$. Similar to the ARBS-F, subscales were most strongly related to attitudes toward lesbians and gay men, frequency of religious attendance, political ideology, and contact with lesbian, gay, and bisexual people in heterosexual samples. Additionally, in lesbians and gay men, the subscales correlated with experiences with bisexual people, desired contact with bisexual people, contact with heterosexual people, and sexual orientation. Other studies using the ARBS-M have reported high internal consistency of the stability subscale $(\alpha=.88$, Kwon $\&$ Hugelshofer, 2012; $\alpha=.92$, Morales Knight $\&$ Hope, 2012; $\alpha=.88$, Tebbe, Moradi, \& Ege, 2014; $\alpha=.90$, Worthington et al., 2005; $\alpha=.91$ Zivony \& Lobel, 2014). In the current study, the ARBS-M stability subscale was found to have high internal consistency reliability (6 items; $\alpha=.90)$. 


\section{Demographic Questionnaire}

A demographic questionnaire (See Appendix F) created by the author was included to gather information about the participants in the study. It contains seven items. The questionnaire collected information on participants' age, gender identity, sexual orientation, race/ethnicity, current relationship status, current U.S. state of residence, and highest completed level of education. Participants were provided with forced-choice options for each question except for age, which was open ended.

\section{Procedures}

A sample of participants was drawn from users of MTurk. Paolacci et al. (2010) reported several advantages and disadvantages to using MTurk. Advantages include the ability to quickly recruit participants (the authors were able to recruit 1000 participants in three weeks), anonymity of participants, and prescreening of participants. There are also several disadvantages. Although the authors reported that MTurk is generally representative of the general population, using MTurk does not ensure a representative sample. Also, as is problematic with all online surveys, there is no way to ensure that participants are staying attentive throughout, which can impact the accuracy of participants' answers. However, a manipulation check requiring participants to correctly identify the name of the person in their vignette and that person's sexual orientation was completed by all participants. This provided evidence participants were attentive while reading their vignettes.

After reading the informed consent form (See Appendix G), participants began the survey. Participants were randomly assigned into one of the six different conditions by the survey created in Qualtrics. In each condition participants read a vignette describing a person in a relationship. The conditions were as follows: 
Condition One: A heterosexual man in a different-gender relationship.

Condition Two: A heterosexual woman in a different-gender relationship.

Condition Three: A bisexual man in a same-gender relationship.

Condition Four: A bisexual man in a different-gender relationship.

Condition Five: A bisexual woman in a same-gender relationship.

Condition Six: A bisexual woman in a different-gender relationship.

After reading the vignettes, participants completed a manipulation check asking them to identify the name and sexual orientation of the person they just read about in the vignette. Next, participants either completed the TI (Dunn \& Schweitzer, 2005) with instructions to complete it in response to the person in their vignette or either the ARBS-F or the ARBS-M (Mohr \& Rochlen, 1999), depending on the gender of the person in the vignette. These measures were counterbalanced. Last, participants completed the demographic questionnaire. They were then shown a thank you debriefing screen (See Appendix H) and were paid twenty-five cents through MTurk's system.

\section{Analysis}

Using SPSS (IBM, 2016), descriptive statistics of the participants in the sample were calculated first using the demographic information provided. Individuals who did not complete the TI and/or the ARBS-M/F, those who failed the manipulation check, and non-heterosexual participants were excluded from the data analysis of this study. Nine hypotheses were then tested.

Using a $2 \times 2$ design with the independent variables of type of relationship and gender and a dependent variable of stability, excluding heterosexual conditions: 


\section{Hypothesis One}

After excluding heterosexual conditions, there will be a main effect for type of relationship in that same gender relationships will be rated as less stable than different gender relationships. This hypothesis was tested with a $2 \times 2$ between-subjects ANOVA with type of relationship (i.e.,, same gender or different gender) serving as the independent variable and mean ratings of stability as measured by the ARBS-F or ARBS-M (Mohr \& Rochlen, 1999) serving as the dependent variable.

\section{Hypothesis Two}

After excluding heterosexual conditions, there will be a main effect for gender in that bisexual women will be rated as less stable than bisexual men. This hypothesis was tested with a 2x2 between-subjects ANOVA with gender (i.e.,, male or female) serving as the independent variable and mean ratings of stability as measured by the ARBS-F or ARBS-M (Mohr \& Rochlen, 1999) serving as the dependent variable.

\section{Hypothesis Three}

After excluding heterosexual conditions, there will be an interaction effect for type of relationship and gender indicating that bisexual women in same gender relationships would be rated the lowest in stability. This hypothesis was tested with a $2 \times 2$ between-subjects ANOVA with type of relationship (i.e.,, same or different-gender) and gender (i.e.,, male or female) serving as the independent variables and mean ratings of stability as measured by the ARBS-F or ARBS-M (Mohr \& Rochlen, 1999) serving as the dependent variable.

Using a $2 \times 2$ design with the independent variables of type of relationship and gender and a dependent variable of trustworthiness, excluding heterosexual conditions. 


\section{Hypothesis Four}

After excluding heterosexual conditions, there will be a main effect for type of relationship in that bisexual individuals in different gender relationships will be rated as less trustworthy than bisexual individuals in same gender relationships. This hypothesis was tested with a $2 \times 2$ between-subjects ANOVA with type of relationship (i.e.,, same gender or different gender) serving as the independent variable and mean ratings of trustworthiness as measured by the TI (Dunn \& Schweitzer, 2005) serving as the dependent variable.

\section{Hypothesis Five}

After excluding heterosexual conditions, there will be a main effect for gender in that bisexual men will be rated as less trustworthy than bisexual women. This hypothesis was tested with a 2x2 between-subjects ANOVA with gender (i.e.,, male or female) serving as the independent variable and mean ratings of trustworthiness as measured by the TI (Dunn \& Schweitzer, 2005) serving as the dependent variable.

\section{Hypothesis Six}

After excluding heterosexual conditions, there will be an interaction effect for type of relationship and gender such that bisexual men in different gender relationships will be rated as the least trustworthy. This hypothesis was tested with a $2 \times 2$ between-subjects ANOVA with type of relationship (i.e.,, same or different-gender) and gender (i.e.,, male or female) serving as the independent variables mean ratings of trustworthiness as measured by the TI (Dunn \& Schweitzer, 2005) serving as the dependent variable.

Using a 2 x 2 design with the independent variables of gender sexual orientation and a dependent variable of trustworthiness: 


\section{Hypothesis Seven}

There will be a main effect for gender in that women will be rated as less trustworthy than men. This hypothesis was tested with a 2x2 between-subjects ANOVA with gender (i.e.,, male or female) serving as the independent variable and mean ratings of trustworthiness as measured by the TI (Dunn \& Schweitzer, 2005) serving as the dependent variable.

\section{Hypothesis Eight}

There will be a main effect for sexual orientation in that bisexual individuals will be rated as less trustworthy than heterosexual individuals. This hypothesis was tested with a $2 \times 2$ between-subjects ANOVA with sexual orientation (i.e.,, heterosexual or bisexual) serving as the independent variable and mean ratings of trustworthiness as measured by the TI (Dunn \& Schweitzer, 2005) serving as the dependent variable.

\section{Hypothesis Nine}

There will be an interaction effect for gender and sexual orientation such that bisexual women will be rated as the least trustworthy overall. This hypothesis was tested with a $2 \times 2$ between-subjects ANOVA with gender (i.e.,, male or female) and sexual orientation (i.e.,, heterosexual or bisexual) serving as the independent variables and mean rating of trustworthiness as measured by the TI (Dunn \& Schweitzer, 2005) serving as the dependent variable. 


\section{CHAPTER 3: RESULTS}

The purpose of this study was to investigate if heterosexual individuals consider romantic relationships to differ in stability and trustworthiness depending upon a person's sexual orientation, their gender, and if the relationship is same or different gender.

The independent variables in this study were gender, sexual orientation, and type of relationship, each with two levels (i.e.,, male or female, heterosexual or bisexual, same-gender or different-gender). The dependent variables in the study were trustworthiness and stability. Nine hypotheses were proposed:

Using a 2 x 2 design with the independent variables of type of relationship and gender and a dependent variable of stability, with only the bisexual conditions:

1. After excluding heterosexual conditions, there will be a significant main effect for type of relationship, in that same gender relationships will be rated as less stable than different gender relationships.

2. After excluding heterosexual conditions, there will be a main effect for gender in that bisexual women will be rated as less stable than bisexual men.

3. After excluding heterosexual conditions, there will be an interaction effect for type of relationship and gender indicating that bisexual women in same gender relationships will be rated the lowest in stability.

Using a 2 x 2 design with the independent variables of type of relationship and gender a dependent variable of trustworthiness, with only the bisexual conditions:

4. After excluding heterosexual conditions, there will be a main effect for type of relationships in that bisexual individuals in different gender relationships will be rated as less trustworthy than bisexual individuals in same gender relationships. 
5. After excluding heterosexual conditions, there will be a main effect for gender in that bisexual men will be rated as less trustworthy than bisexual women.

6. After excluding heterosexual conditions, there will be an interaction effect for type of relationship and gender such that bisexual men in different gender relationships will be rated as the least trustworthy.

Using a $2 \times 2$ design with the independent variables of gender and sexual orientation and a dependent variable of trustworthiness:

7. There will be a main effect for gender in that women will be rated as less trustworthy than men.

8. There will be a main effect for sexual orientation in that bisexual individuals will be rated as less trustworthy than heterosexual individuals.

9. There will be an interaction effect for gender and sexual orientation such that bisexual women will be rated as the least trustworthy overall.

\section{Demographic Data from the Sample}

The final analytical sample consisted of $n=558$ participants, recruited from Amazon's Mechanical Turk. Initially, 1,188 individuals responded to the survey. Of these, 36 did not complete the assessment portions of the survey (i.e.,, left the TI and/or ARBS-M/F blank), 493 did not identify as heterosexual, and 101 failed the manipulation check within the survey and were thus excluded from the analysis. Participants included in the analysis were 58.9\% men, $40.7 \%$ women, $.2 \%$ trans men, and $.2 \%$ genderqueer/gender non-conforming. They ranged in age from 18 to 76 years with an average age of $34.6(S D=11.06)$. The majority of participants identified as White/Caucasian (59.1\%), with 24\% identifying as Asian, $6.4 \%$ identifying as Black/African-American, 6.1\% identifying as Latino/a, 2.9\% identifying as American 
Indian/Alaskan Native, $1.1 \%$ identifying with two or more races, .2\% identifying as Native Hawaiian/Pacific Islander, and .2\% with another race/ethnicity that was not listed. In terms of marital statuses, $45.5 \%$ of participants reported being married currently. The typical highest level of education completed by participants was a Bachelor's degree (47.7\%) (See Table 1). Participants were randomly assigned to the six study conditions with 95 participants in condition one (male, heterosexual, different gender relationship), 92 in condition two (female, heterosexual, different gender relationship), 92 in condition three (male, bisexual, same gender relationship), 99 in condition four (male, bisexual, different gender relationship), 85 in condition five (female, bisexual, same gender relationship), and 95 in condition six (female, bisexual, different gender relationship).

Based on a series of ANOVAs, the demographic characteristics of the participants across conditions did not significantly differ. In regard to age, $F(1,5)=.88, p=.50$, and race/ethnicity, $F(1,5)=.84, p=.52$, the participants did not significantly differ across conditions. Similarly, they did not differ in regard to relationship status, $F(1,5)=.95, p=.45$, or highest completed level of education, $F(1,5)=.46, p=.80$. Participants across conditions did significantly differ in terms of gender across conditions, $F(1,5)=2.43, p=.03$, due to the inclusion of one outlier in condition three (a participant who identified as a trans man). However, when removing this outlier, participants no longer differed significantly across conditions in terms of gender, $F(1,5)$ $=1.66, p=.14$. For a breakdown of demographic information by condition, please see Table 2 .

\section{Major Findings}

This section presents major findings organized around each of the nine hypotheses associated with this study. The survey provided to participants was comprised of five sections. The first section contained one of six vignettes describing a person in a romantic relationship and 
Table 1

Demographic Information

\begin{tabular}{|c|c|c|}
\hline Demographics & $n$ & Percentage \\
\hline \multicolumn{3}{|l|}{ Gender } \\
\hline Man & 329 & 58.9 \\
\hline Woman & 227 & 40.7 \\
\hline Trans man & 1 & .2 \\
\hline Trans woman & 0 & 0 \\
\hline Genderqueer/Gender non-conforming & 1 & .2 \\
\hline Different Gender & 0 & 0 \\
\hline \multicolumn{3}{|l|}{ Race/Ethnicity } \\
\hline White/Caucasian & 330 & 59.1 \\
\hline Black/African-American & 36 & 6.4 \\
\hline American Indian/Alaskan Native & 16 & 2.9 \\
\hline Asian & 134 & 24 \\
\hline Native Hawaiian/Pacific Islander & 1 & .2 \\
\hline Two or more races & 6 & 1.1 \\
\hline Latino/a & 34 & 6.1 \\
\hline Different race/ethnicity & 1 & .2 \\
\hline \multicolumn{3}{|l|}{ Relationship Status } \\
\hline Single, never married or in a domestic/civil partnership & 224 & 40.1 \\
\hline Married & 254 & 45.5 \\
\hline Separated & 7 & 1.3 \\
\hline Divorced & 29 & 5.2 \\
\hline Widowed & 8 & 1.4 \\
\hline Partnered & 17 & 3.1 \\
\hline No response & 19 & 3.4 \\
\hline \multicolumn{3}{|l|}{ Highest Completed Level of Education } \\
\hline High school diploma & 83 & 14.9 \\
\hline GED & 13 & 2.3 \\
\hline Associate's degree & 69 & 12.4 \\
\hline Bachelor's degree & 266 & 47.7 \\
\hline Master's degree & 90 & 16.1 \\
\hline Doctorate degree & 15 & 2.7 \\
\hline Unsure & 0 & 0 \\
\hline Not listed & 3 & .5 \\
\hline No response & 19 & 3.4 \\
\hline Total Participants & 558 & $100 \%$ \\
\hline
\end{tabular}


Table 2

Demographic Information by Condition

\begin{tabular}{|c|c|c|c|c|c|c|}
\hline \multirow[b]{2}{*}{ Demographics } & \multicolumn{6}{|c|}{ Percentages by Condition } \\
\hline & $\begin{array}{c}\text { One } \\
n=95\end{array}$ & $\begin{array}{c}\text { Two } \\
n=92\end{array}$ & $\begin{array}{l}\text { Three } \\
n=92\end{array}$ & $\begin{array}{c}\text { Four } \\
n=99\end{array}$ & $\begin{array}{c}\text { Five } \\
n=85\end{array}$ & $\begin{array}{c}\text { Six } \\
n=95\end{array}$ \\
\hline \multicolumn{7}{|l|}{ Gender Identity } \\
\hline Man & $55.8 \%$ & $57.6 \%$ & $66.3 \%$ & $64.6 \%$ & $60.0 \%$ & $49.5 \%$ \\
\hline Woman & $44.2 \%$ & $42.4 \%$ & $31.5 \%$ & $35.4 \%$ & $40.0 \%$ & $50.5 \%$ \\
\hline Trans man & $0 \%$ & $0 \%$ & $1.1 \%$ & $0 \%$ & $0 \%$ & $0 \%$ \\
\hline Trans woman & $0 \%$ & $0 \%$ & $0 \%$ & $0 \%$ & $0 \%$ & $0 \%$ \\
\hline Genderqueer/Gender non-conforming & $0 \%$ & $0 \%$ & $1.1 \%$ & $0 \%$ & $0 \%$ & $0 \%$ \\
\hline Different Gender & $0 \%$ & $0 \%$ & $0 \%$ & $0 \%$ & $0 \%$ & $0 \%$ \\
\hline \multicolumn{7}{|l|}{ Race/Ethnicity } \\
\hline White/Caucasian & $54.7 \%$ & $62.0 \%$ & $69.6 \%$ & $53.5 \%$ & $58.8 \%$ & $55.8 \%$ \\
\hline Black/African-American & $8.4 \%$ & $5.4 \%$ & $4.3 \%$ & $6.1 \%$ & $8.2 \%$ & $6.3 \%$ \\
\hline American Indian/Alaskan Native & $2.1 \%$ & $1.1 \%$ & $1.1 \%$ & $3.0 \%$ & $5.9 \%$ & $4.2 \%$ \\
\hline Asian & $24.2 \%$ & $27.2 \%$ & $18.5 \%$ & $31.3 \%$ & $18.8 \%$ & $23.2 \%$ \\
\hline Native Hawaiian/Pacific Islander & $1.1 \%$ & $0 \%$ & $0 \%$ & $0 \%$ & $0 \%$ & $0 \%$ \\
\hline Two or more races & $3.2 \%$ & $0 \%$ & $1.1 \%$ & $1.0 \%$ & $0 \%$ & $1.1 \%$ \\
\hline Latino/a & $6.3 \%$ & $3.2 \%$ & $5.4 \%$ & $5.1 \%$ & $8.2 \%$ & $8.4 \%$ \\
\hline Different race/ethnicity & $0 \%$ & $1.1 \%$ & $0 \%$ & $0 \%$ & $0 \%$ & $0 \%$ \\
\hline \multicolumn{7}{|l|}{ Relationship Status } \\
\hline $\begin{array}{l}\text { Single, never married } \\
\text { or in a domestic/civil partnership }\end{array}$ & $43.2 \%$ & $41.3 \%$ & $42.4 \%$ & $43.4 \%$ & $38.8 \%$ & $31.6 \%$ \\
\hline Married & $43.2 \%$ & $46.7 \%$ & $42.4 \%$ & $41.4 \%$ & $45.9 \%$ & $53.7 \%$ \\
\hline Separated & $0 \%$ & $1.1 \%$ & $2.2 \%$ & $0 \%$ & $3.5 \%$ & $1.1 \%$ \\
\hline Divorced & $4.2 \%$ & $2.2 \%$ & $6.5 \%$ & $7.1 \%$ & $4.7 \%$ & $6.3 \%$ \\
\hline Widowed & $2.1 \%$ & $1.1 \%$ & $0 \%$ & $1.0 \%$ & $2.4 \%$ & $2.1 \%$ \\
\hline Partnered & $6.3 \%$ & $0 \%$ & $5.4 \%$ & $3.0 \%$ & $2.4 \%$ & $1.1 \%$ \\
\hline No response & $1.1 \%$ & $7.6 \%$ & $1.1 \%$ & $4.1 \%$ & $2.4 \%$ & $4.2 \%$ \\
\hline
\end{tabular}


Table 2 Continued

\begin{tabular}{lcccccc}
\hline \multicolumn{1}{c}{ Demographics } & \multicolumn{5}{c}{ Percentages by Condition } \\
\hline & $\begin{array}{c}\text { One } \\
\mathrm{n}=95\end{array}$ & $\begin{array}{c}\text { Two } \\
\mathrm{n}=92\end{array}$ & $\begin{array}{c}\text { Three } \\
\mathrm{n}=92\end{array}$ & $\begin{array}{c}\text { Four } \\
\mathrm{n}=99\end{array}$ & $\begin{array}{c}\text { Five } \\
\mathrm{n}=85\end{array}$ & $\begin{array}{c}\text { Six } \\
\mathrm{n}=95\end{array}$ \\
\hline Highest Completed Level of Education & & & & & & \\
$\quad$ High school diploma & $20 \%$ & $17.4 \%$ & $14.1 \%$ & $8.1 \%$ & $17.6 \%$ & $12.6 \%$ \\
GED & $1.1 \%$ & $2.2 \%$ & $1.1 \%$ & $3.0 \%$ & $2.4 \%$ & $4.2 \%$ \\
Associate's degree & $10.5 \%$ & $7.6 \%$ & $12.0 \%$ & $16.2 \%$ & $15.3 \%$ & $12.6 \%$ \\
Bachelor's degree & $42.1 \%$ & $45.6 \%$ & $50.0 \%$ & $49.5 \%$ & $43.5 \%$ & $54.7 \%$ \\
Master's degree & $18.9 \%$ & $18.5 \%$ & $16.3 \%$ & $17.2 \%$ & $15.3 \%$ & $10.5 \%$ \\
Doctorate degree & $4.2 \%$ & $0 \%$ & $5.4 \%$ & $2.0 \%$ & $3.5 \%$ & $1.1 \%$ \\
Unsure & $0 \%$ & $0 \%$ & $0 \%$ & $0 \%$ & $0 \%$ & $0 \%$ \\
Not listed & $2.1 \%$ & $1.1 \%$ & $0 \%$ & $0 \%$ & $0 \%$ & $0 \%$ \\
No Response & $1.1 \%$ & $7.6 \%$ & $1.1 \%$ & $4.0 \%$ & $2.4 \%$ & $4.2 \%$ \\
\hline Total Participants & $100 \%$ & $100 \%$ & $100 \%$ & $100 \%$ & $100 \%$ & $100 \%$ \\
\hline
\end{tabular}


the second was a manipulation check to ensure participants understood who the vignette described and their sexual orientation. The third and fourth sections contained the TI (Dunn \& Schweitzer, 2005) and either the ARBS-F or ARBS-M (Mohr \& Rochlen, 1999) and were counterbalanced. Finally, the fifth section requested demographic information including age, gender identity, sexual orientation, race/ethnicity, current relationship status, current U.S. state of residence, and highest completed level of education. Data were analyzed using SPSS 24.0 (IBM, 2016). The following are sections exploring the major findings of this study organized by hypothesis.

\section{Hypotheses One Through Three}

The first set of analyses included the dependent variable of stability and the independent variables of type of relationship and gender. Heterosexual conditions were excluded as the ARBS-M/F only measure perceptions of stability of bisexuals, not heterosexuals and also because heterosexual conditions only include different gender relationships, so they cannot be compared to same gender heterosexual relationships. A factorial, two-way ANOVA was conducted to test these hypotheses.

Hypothesis one. It was hypothesized that, after excluding heterosexual conditions, there would be a main effect for type of relationship, in that same gender relationships would be rated as less stable than different gender relationships. A factorial, two-way ANOVA indicated that in bisexual conditions, there was no significant main effect for type of relationship in terms of stability, $F(1,370)=.27, p=.60$. Thus, bisexual individuals in same $(M=3.36, S D=1.03)$ and different gender $(M=3.31, S D=1.07)$ relationships were not perceived statistically differently in terms of stability. 
Hypothesis two. It was hypothesized that, after excluding heterosexual conditions, there would be a main effect for gender in that bisexual women would be rated as less stable than bisexual men. A factorial, two-way ANOVA indicated that, in bisexual conditions, there was no significant main effect for gender in terms of stability, $F(1,370)=1.82, p=.18$. Thus, bisexual men $(M=3.26, S D=1.08)$ and women $(M=3.40, S D=1.01)$ were not perceived statistically differently in terms of stability.

Hypothesis three. It was hypothesized that, after excluding heterosexual conditions, there would be an interaction effect for type of relationship and gender, indicating that bisexual women in same gender relationships would be rated the lowest in stability. A factorial, two-way ANOVA indicated that there was no significant interaction for type of relationship and gender in terms of stability, $F(1,370)=1.06, p=.31$. Thus, bisexual individuals were not seen as varying in stability based upon their gender or the type of relationship they were in.

\section{Hypotheses Four Through Six}

The second set of analyses included the dependent variable of trustworthiness and the independent variables of type of relationship and gender. Heterosexual conditions were excluded as those conditions only included different gender relationships. A factorial, two-way ANOVA was conducted to test these hypotheses.

Hypothesis four. It was hypothesized that, after excluding heterosexual conditions, there would be a main effect for type of relationship, in that bisexual individuals in different gender relationships would be rated as less trustworthy than bisexual individuals in same gender relationships. A factorial, two-way ANOVA indicated that in bisexual conditions, there was a significant main effect for type of relationship in terms of trustworthiness, $F(1,371)=4.14, p=$ .04. Bisexual individuals in same gender relationships $(M=5.59, S D=.94)$ were rated as more trustworthy than bisexual individuals in different gender relationships $(M=5.37, S D=1.13)$. 
Hypothesis five. It was hypothesized that, after excluding heterosexual conditions, there would be a main effect for gender, in that bisexual men would be rated as less trustworthy than bisexual women. A factorial, two-way ANOVA indicated that in bisexual conditions there was no significant main effect for gender in terms of trustworthiness, $F(1,371)=1.04, p=.31$. Thus, the bisexual person's gender (men, $M=5.53, S D=1.06$; women, $M=5.41, S D=1.03$ ) did not statistically significantly impact perceptions of trustworthiness.

Hypothesis six. It was hypothesized that, after excluding heterosexual conditions, there would be an interaction effect for type of relationship and gender, such that bisexual men in different gender relationships would be rated as the least trustworthy. A factorial, two-way ANOVA indicated that there was no statistically significant interaction for gender and type of relationship in terms of trustworthiness, $F(1,371)=1.44, p=.23$. Thus, bisexual individuals were not rated as statistically significantly different in terms of trustworthiness when considering both their gender and the type of relationship they were in.

\section{Hypotheses Seven Through Nine}

The final set of analyses included the dependent variable of trustworthiness and the independent variables of type of gender and sexual orientation. All conditions were included. A factorial, two-way ANOVA was conducted to test these hypotheses.

Hypothesis seven. It was hypothesized that there would be a main effect for gender, in that women would be rated as less trustworthy than men. A factorial, two-way ANOVA indicated that there was no significant main effect for gender in terms of trustworthiness, $F(1$, $558)=.33, p=.57$. Men $(M=5.46, S D=1.08)$ and women $(M=5.46, S D=1.03)$ were rated as similar on trustworthiness.

Hypothesis eight. It was hypothesized that there would be a main effect for sexual orientation, in that bisexual individuals would be rated as less trustworthy than heterosexual 
individuals. A factorial, two-way ANOVA indicated that there was no statistically significant main effect for sexual orientation in terms of trustworthiness, $F(1,558)=.29, p=.59$. Bisexual $(M=5.47, S D=1.05)$ and heterosexual $(M=5.42, S D=1.08)$ individuals were rated as similar on trustworthiness.

Hypothesis nine. It was hypothesized that there would be an interaction effect for gender and sexual orientation, such that bisexual women would be rated as the least trustworthy overall. A factorial, two-way ANOVA indicated that there was no statistically significant interaction for gender and sexual orientation in terms of trustworthiness, $F(1,558)=3.33, p=.07$. When considering gender and sexual orientation, individuals were not perceived differently in terms of trustworthiness.

\section{Additional Analyses}

Significant findings were explored in more depth to ensure they did not violate the assumptions of the ANOVA. Non-significant findings were not explored further, as violations in the assumptions of the ANOVA typically lead to Type I errors, not Type II errors (Glass, Peckham, \& Sanders, 1972). Thus, because the findings were statistically non-significant, there is no concern that a Type I error was committed. Due to this, only hypothesis four, with the significant finding, was explored in more depth.

A factorial two-way ANOVA has several assumptions. These include independence of cases, meaning that each sample has been drawn independently of one another, normality, meaning that the samples were drawn from normally distributed populations, and homogeneity of variance, meaning that the variances within each sample should be the same (Refinetti, 1996).

The assumption of independence of cases was managed by random assignment into conditions and a sample collection without systematic bias (somewhat random). However, initially both the assumption of normality and homogeneity of variance were violated. 
A Shapiro-Wilk test was used to test the assumption of normality and was chosen over a Kolmogorov-Smirnov test due to the small sample size (Guo, 2012). None of the independent groups were normally distributed: condition three $(W=.95, p<.01)$, condition four $(W=.94, p<$ $.01)$, condition five $(W=.93, p<.01)$, condition six $(W=.95, p<.01)$. To manage this assumption violation, hypothesis four was re-tested with an independent samples $t$-test. An independent samples $t$-test was chosen because it is more robust than ANOVAs and is less impacted by non-normal data. The estimator used in $t$-tests for the standard error of the sample means remains consistent regardless of the distribution of the data and therefore is not impacted by normality (Lumley, Diehr, Emerson, \& Chen, 2002). Additionally, using the Central Limit Theorem, although the data in this sample appear to be non-normative, if repeated sampling were to occur, the data would eventually converge to a normal distribution (Brooks, 2012).

An independent samples $t$-test indicated that hypothesis four was still statistically significant, $t(369)=2.0, p=.04$. After excluding heterosexual conditions, bisexual individuals in same gender relationships $(M=5.59, S D=.94)$ were rated as more trustworthy than bisexual individuals in different gender relationships $(M=5.37, S D=1.13)$.

Also violated in the original two-way ANOVA was the assumption of homogeneity of variance. A Levene's test of equality of error variances indicated that the variances were unequal, $F(1,3)=3.29, p=.02$. To manage this assumption violation, the hypothesis was tested using a one-way Welch's ANOVA. The Welch's ANOVA does not assume that variances are equal and its statistical power is nearly equal to that of a one-way ANOVA (Kohr \& Games, 1974).

A one-way Welch's ANOVA also indicated that hypothesis four was statistically significant, $F(1,365)=4.09, p=.04$. After excluding heterosexual conditions, bisexual 
individuals in same gender relationships $(M=5.59, S D=.94)$ were rated as more trustworthy than bisexual individuals in different gender relationships $(M=5.37, S D=1.13)$.

To determine if the lack of statistically significant results was a result of poor statistical power, a post hoc power analysis using $\mathrm{G}^{*}$ Power (Faul et al., 2007) was completed. The power analysis indicated a 99\% chance of detecting a moderate effect size (.025) as significant between groups at the $5 \%$ level.

\section{Summary}

In summary, no statistically significant results were found concerning the dependent variable of stability. Participants did not consider bisexual individuals to differ in levels of stability depending upon their gender or the type of relationship they were in. Additionally, in terms of the dependent variable of trustworthiness no significant differences were found in terms of sexual orientation or gender. Thus, participants did not consider bisexual and heterosexual individuals or men and women to differ in terms of trustworthiness. However, participants did rate bisexuals differently in terms of trustworthiness depending upon the type of relationship they were in. Bisexual individuals in same gender relationships are viewed as significantly more trustworthy than bisexual individuals in different gender relationships (same gender, $M=5.59$, $S D=.94$; different gender, $M=5.37, S D=1.13$ ). These findings and how they relate to the literature on these topics will be discussed further in the next chapter. 


\section{CHAPTER 4: SUMMARY AND DISCUSSION}

The current study explored heterosexual individuals' perceptions of both stability and trustworthiness in bisexual individuals. No differences were found in perceptions of stability between bisexual men and women or between bisexual individuals in same or different gender relationships. Additionally, no differences were found in perceptions of trustworthiness between men and women or heterosexual individuals and bisexual individuals. However, perceptions of trustworthiness did differ between bisexual individuals in same or different gender relationships. Participants tended to perceive bisexual individuals in same gender relationships as more trustworthy than those in different gender relationships.

This chapter will discuss these findings and provide possible explanations for the results, limitations of the current study, and conclude with recommended future directions in this area of study.

\section{Discussion of Stability in Bisexual Relationships (Hypotheses 1-3)}

It was hypothesized that after excluding heterosexual conditions, same gender relationships would be rated as less stable than different gender relationships, bisexual women would be rated as less stable than bisexual men, and that bisexual women in same gender relationships would be rated as the lowest in stability. However, a factorial two-way ANOVA indicated that none of these hypotheses are statistically significant, meaning that there was no difference in perceptions of stability between bisexual men or bisexual women, regardless of if they were in a same or different gender relationship.

These results do not necessarily conflict with prior research on perceptions of stability in bisexual populations. Bisexuality has been described as an "in between" (Bostwick \& Hequembourg, 2014; Hequembourg \& Brallier, 2009), inauthentic (Israel \& Mohr, 2004), and temporary (Alaire \& Gaudet, 2013) sexual orientation in comparison to monosexual orientations. 
But no research has demonstrated that the stereotype of bisexuality as an instable sexual orientation is perceived differently depending upon the type of relationship or gender of the bisexual person in question.

However, there has been research demonstrating that the stereotypes associated with bisexuality look different when applied to bisexual men and women. Specifically, a study by Flanders and Hatfield (2014), suggested that participants considered those who have had at least one romantic or sexual experience with someone from the same and different gender to be bisexual. However, when examining the open-ended responses, it was discovered that there were differing patterns. Participants hesitated to label women as bisexual and instead tended to consider them heterosexual, but "bicurious." Alternatively, participants hesitated to label men as bisexual as well, but instead tended to consider them to be gay. In Flanders and Hatfield's (2014) study, there certainly appear to be differences in perceptions of sexual orientation stability in bisexual men and women, but it is not necessarily in the level or amount of relationship instability.

Other researchers have also found that bisexual women are more likely to be considered heterosexual than gay or bisexual (Alaire \& Gaudet, 2013; Dyar et al., 2017; Esterline \& Galupo, 2013; Lanutti \& Denes, 2012; Rupp \& Taylor, 2010) and that bisexual men are more likely to be considered gay than bisexual or heterosexual (Alaire \& Gaudet, 2013; Anderson \& Adams, 2011). This discrepancy has been suggested to be related to specific stereotypes concerning bisexual men and women's motives behind their sexual orientations. Specifically, bisexual women participating in same gender behaviors are often considered to be performing for men's sexual gratification and are therefore heterosexual (Esterline \& Galupo, 2013; Lanutti \& Denes, 2012; Rupp \& Taylor, 2010). For example, in Flanders and Hatfield's (2014) study, participants 
noted that they believed bisexual men were truly gay, but afraid to come out as such or had not truly accepted who they were yet.

The current findings add to the brief literature on perceptions of stability in men and women who identify as bisexual. There continues to be no evidence that there are perceived differences in perceptions of stability overall. Past research has demonstrated that perceptions of stability are more dependent on the perceiver's gender (e.g.,, heterosexual men have reported perceiving female bisexuality as more stable than male bisexuality while heterosexual women have reported no difference in perceptions [Mohr \& Rochlen, 1999]) or sexual orientation (e.g.,, Lesbian women perceived female bisexuality as less stable than male bisexuality and gay men perceived male bisexuality as less stable than female bisexuality [Mohr \& Rochelen, 1999]). Additionally, as noted above, past research has suggested that there is a perception that bisexuality is an unstable sexual orientation. However, although past studies have suggested it manifests differently depending upon gender, its perception does not necessarily differ significantly between genders.

\section{Discussion of Trustworthiness in Bisexual Relationships (Hypotheses 4-6)}

It was hypothesized that after excluding heterosexual conditions, bisexual individuals in different gender relationships would be rated as less trustworthy than those in same gender relationships, bisexual men would be rated as less trustworthy than bisexual women, and bisexual men in different gender relationships would be considered the least trustworthy overall. A factorial two-way ANOVA indicated that bisexual individuals in different gender relationships were rated as less trustworthy than those in same gender relationships, but that there were no further differences between groups. Thus, bisexual individuals dating someone of the same gender were considered to be more trustworthy than bisexual individuals dating someone of another gender, but bisexual men and bisexual women were not perceived as more or less 
trustworthy of one another, regardless of the type of relationship they were in. These results were also somewhat commensurate with past research on bisexuality.

Integrated threat theory (Stephan \& Stephan, 2000) is useful when exploring why heterosexual participants may have perceived bisexual individuals in different gender relationships as less trustworthy than those in same gender relationships. According to integrated threat theory, prejudices and implementations of stereotypes can develop from any perceived threat toward members of one's own group. Therefore, when considering the vignettes in the current study, the stereotype of trustworthiness or any prejudices in terms of mistrust may not be activated or considered when a bisexual individual is dating someone of the same gender who can also be presumed to not be heterosexual. However, when considering how someone from the participants' in group (i.e., heterosexual) may be impacted, stereotypes may arise or be emphasized. Zivony and Lobel (2014) also used this theory to suggest why in their study the most consistent and harmful stereotypes for bisexuals were applied to bisexual men dating women. They noted that, similar to the current study, heterosexual participants may not have had several stereotypes or prejudices activated when considering a bisexual man dating another man who was not heterosexual and therefore not within their in group. However, once an assumed member of the in group could be impacted (i.e., heterosexual women), prejudices and stereotypes were activated, impacting perceptions of bisexual men.

Past research exploring perceptions of bisexual individuals also supports this finding within the context of integrated threat theory and trust within romantic relationships. Armstrong and Reissing (2014) found that heterosexual women reported worry that if they were to date a bisexual man, he would cheat on them or leave them for another man. In this same vein, research has suggested that there is fear that bisexual individuals will be unfaithful in their relationships (Alaire \& Gaudet, 2013; Brewster \& Moradi, 2010; Eliason, 1997, 2001; Fahs, 
2009; Gustavson, 2009; Herek, 2002; Israel \& Mohr, 2004; Lanutti \& Denes, 2012; McLean, 2004; Mint, 2004; Mohr \& Rochlen, 1999). More specifically, there has been reported fear that bisexual men in different gender relationships will be unfaithful, catch an STI, and then infect their heterosexual, female partners (Spalding \& Peplau, 1997).

Mistrust of bisexual partners is not just evidenced by heterosexual individuals. Feinsten et al. (2014) found that heterosexual, gay, and lesbian individuals all reported being less likely to engage in a relationship with a bisexual partner than a partner with their same sexual orientation. Bostwick and Hequembourg (2014) also noted that their bisexual participants reported those in gay, lesbian, and heterosexual communities ending relationships with them once they disclosed their sexual orientation. These studies, in addition to the current study's finding that heterosexual participants considered bisexuals in different gender (e.g., "heterosexual") relationships to be less trustworthy, indicate that perceptions of trust may be founded on the basis of how the person in question can impact the in group. According to integrated threat theory (Stephan \& Stephan, 2000), binegative beliefs may be activated or heightened when members of the in-group's well-being is threatened.

The non-significant results related to perceptions of trustworthiness between bisexual men and women, were also somewhat commensurate with past research. Historically, research has not explored overall differences in trustworthiness between bisexual men and women, but has instead focused upon perceived trustworthiness between bisexual individuals and heterosexual individuals. Or, when gender is being examined, researchers have tended to choose a gender to study (e.g., Bostwick \& Hequembourg, 2014; Zivony \& Lobel, 2014) and then explore the differences between perceptions of bisexuality and heterosexuality through that lens. For example, in Zivony and Lobel's (2014) study exploring perceptions of bisexual men, they found that heterosexual participants considered bisexual men to be the least trustworthy of all 
sexual orientations and in Bostwick and Hequembourg's (2014) qualitative research, several female bisexual participants shared anecdotes describing partners ending relationships, citing mistrust, after the participants shared their sexual orientation. These studies suggest that both male and female bisexual individuals are considered to be untrustworthy, but perhaps not more or less than each other or perhaps in different ways.

Another consideration is that male and female bisexual individuals may be considered more or less trustworthy depending upon the audience. For example, Armstrong and Reissing (2014) reported that heterosexual women reported worry that a male bisexual partner might cheat on them or leave them for a man. However, in Blumstein and Schwartz's (1974) work with the radical lesbian feminist movement, they noted that at that time, lesbians mistrusted bisexual women, not because they may cheat on them, but due to the political weight and meaning of being in a same gender relationship. There was reported fear that a bisexual woman could retreat into a different gender relationship and abandon any oppression or discrimination that was associated with being in a same gender relationship. Therefore, it appears that there likely are differences between levels and perceptions of types of trust between male and female bisexuals; however, it is difficult to identify these differences when using a broad conceptualization of trust and a broad audience (i.e., only heterosexuals).

As such, the current nonsignificant results contribute to the existing research on mistrust of bisexual individuals by reaffirming that when observed broadly, heterosexual individuals do not appear to perceive male and female bisexuals as different in terms of trust. However, when examined in more depth, differences in perceptions of trust do arise that are dependent upon other variables. For example, in Armstrong and Ressing's (2014) study, heterosexual women considered bisexual men to be less trustworthy than heterosexual men considered bisexual women. However, in their study, the heterosexual men surveyed expressed interest in the 
possibility that a bisexual female partner would lead to new sexual experiences, whereas this was not as important for the female participants. Heterosexual women reported concern that their well-being would be impacted; heterosexual men reported excitement for new sexual experiences.

Additionally, similar to stability, past research has demonstrated that trustworthiness is viewed through different lenses when applied to male and female bisexual individuals. For example, bisexual men are sometimes considered to be lying about their sexual orientation, which leads to perceptions of deception and hiding truths, while bisexual women are sometimes considered to be performing for male pleasure and attention (Yost \& Thomas, 2012). The current study supports past research and the idea that there may not be a broad difference in perceptions of levels of trustworthiness between bisexual men and women and will hopefully spur future research exploring what factors do contribute to perceptions of mistrust in bisexual individuals.

\section{Discussion of Trustworthiness Overall (Hypotheses 7-9)}

It was hypothesized that when including all conditions, women would be rated as less trustworthy than men, bisexuals would be rated as less trustworthy than heterosexuals, and that bisexual women would be considered the least trustworthy overall. A factorial two-way ANOVA indicated there were no statistically significant differences between these groups. This means that no differences in perceptions of trust were found between men and women, regardless of sexual orientation or between bisexual individuals and heterosexual individuals, regardless of gender. These results are incongruent with prior research. Past research has demonstrated that those who identify as bisexual are considered less trustworthy and more likely to be unfaithful in relationships than those who identify as heterosexual (Brewster \& Moradi, 2010; Eliason, 1997; Eliason, 2001; Fahs, 2009; Gustavson, 2009; Herek, 2002; Israel \& Mohr, 
2004; Lanutti \& Denes, 2012; McLean, 2004; Mint, 2004; Mohr \& Rochlen, 1999; Spalding \& Peplau, 1997; Zivony \& Lobel, 2014).

However, there could be several explanations for the lack of differences between groups. Firstly, the most recent study exploring trustworthiness in bisexuals was completed by Zivony and Lobel in 2014. Although they reported that bisexual men were evaluated as less trustworthy than all other non-bisexual men, they described the result as only "marginally significant" $(F(1$, $223)=3.77, p=.026$ ). It is possible that stereotypes are changing or fading as the public's understanding of bisexuality, and non-heterosexual sexual orientations in general, are evolving. Additionally, the average age in the current study was relatively young (34.6 years old) and older age is associated with higher levels of binegativity (Herek, 2002; Mohr \& Rochlen, 1999). Also, heterosexual individuals who know a bisexual person are less likely to endorse binegative beliefs or negative stereotyping (Eliasion, 1997; Lytle, Dyar, Levy, \& London, 2017). It is possible that with recent political advances, bisexuality has become a more visible sexual orientation and that more bisexual individuals are being open about their sexual orientation. Therefore, more heterosexual individuals may know a bisexual person leading to less endorsement of harmful stereotyping.

\section{Limitations}

While the current findings add to the scholarship on heterosexual perceptions of bisexuals, there are several limitations in the current study. First, was not obtained using random sampling techniques. For example, all participants in the current study not only had internet access, but also were Amazon Mechanical Turk (MTurk) users. This limits the pool of possible participants to individuals with internet access and who actively use MTurk. This population may share some unique characteristics that were not controlled for within the current study. 
Therefore, the results have limited external validity and may not be fully generalizable to a population outside of MTurk.

As mentioned in the participants section, users of MTurk are more often White (Huff \& Tingley, 2015), women, and those reporting a higher education level than the general population (Paolacci et al., 2010). Aside from gender demographics (more men than women participated in the study), these demographics were reflected in the study sample. Therefore, not only may the results not be generalizable to populations outside of MTurk, but they should also be interpreted with caution with respect to those without post-secondary degrees. Previous research has indicated that heterosexuals with higher levels of education exhibit greater levels of ally behaviors to the LGBTQ+ population (Fingerhut, 2011) as well as participate in more activism for and with the LGBTQ+ community (Jones \& Brewster, 2017). Additionally, just knowing a bisexual person has been found to decrease stereotyping and biphobia among heterosexuals (Eliason, 1997; Lytle et al., 2017) and it is possible that those who attend colleges and universities have an opportunity to meet people who identify as bisexual openly. Many colleges and universities have LGBTQ+ student groups and/or LGBTQ+ Centers (College Equality Index, n.d.) which provides more visibility for LGBTQ+ students, thus exposing heterosexual students to the idea of bisexuality.

Additionally, given the possibility that biphobic and/or heterosexist attitudes are becoming less accepted, the current study may have suffered from social desirability bias. Social desirability bias refers to participants' tendency to distort answers to present themselves in a more socially positive manner (DeVillis, 2003). For example, a participant may be less likely to trust a bisexual person over a heterosexual person or a woman over a man, but they may be aware that this behavior is biphobic or sexist. Thus, to avoid any feelings of guilt or shame associated with these types of beliefs or behaviors, participants may falsely or underreport their 
own biases and beliefs (Jann, Jerke, \& Krumpal, 2012). Anonymity cannot always avoid social desirability bias from impacting results in self-report measures, as negative feelings such as guilt or shame are enough to lead a person to present themselves in a more favorable and socially tolerant light (Jann et al., 2012).

The vignettes in the current study may also have impacted results in unexpected ways. In terms of stability, the individual in the vignettes did not fit the stereotype of a woman performing a same gender behavior for the gratification of a man (i.e., women in the vignettes were in committed relationships, not expressing attraction or performing any romantic behaviors) which may have impacted perceptions of stability according to research concerning the idea of performative bisexuality in women (Esterline \& Galupo, 2013; Lanutti \& Denes, 2012; Rupp \& Taylor, 2010). Also, the individual in the vignette was portrayed as confident in their relationship, which may have impacted any perceptions that male individuals in the vignette were unsure or "hiding" their sexual orientation (Yost \& Thomas, 2012).

Additionally, bisexual individuals who have not had both same and different gender partners, yet have expressed attraction to more than one gender, have also been considered as not having a "stable" sexual orientation (Alaire \& Gaudet, 2013; Boyer \& Galupo, 2015). In the vignettes provided in the current study, the bisexual individuals had been in relationships with both men and women. This may have impacted perceptions of stability of their sexual orientation as well.

The scales used in the current study may also have impacted results. The Attitudes Regarding Bisexuality Scale (ARBS-M/F; Mohr \& Rochlen, 1999) only measures attitudes regarding bisexuality. Therefore, it was not used to measure participants' attitudes toward heterosexuals in the first two conditions and no comparison in terms of stability could be made between heterosexuals and bisexuals. There is currently no scale measuring the same construct 
of stability as the ARBS-M/F (Mohr \& Rochlen, 1999) of heterosexual individuals. This is problematic because without a scale measuring the same construct with heterosexual individuals, there is no empirically validated way to determine if lack of stability is a unique stereotype only applied to the bisexual community. Qualitative research has suggested this (Bostwick \& Hequembourg, 2014) and quantitative research has suggested that this stereotype does impact the bisexual community (Mohr \& Rochlen, 1999), but there is no way to find comparative data within the majority population (i.e., heterosexuals).

In terms of the construct of trust, although many researchers have noted that bisexuals are considered less trustworthy than heterosexuals (Gustavson, 2009; Israel \& Mohr, 2004; Klesse, 2005; McLean, 2004; Mohr \& Rochlen, 1999; Spalding \& Peplau, 1997), there are currently no scales that quantitatively measure this construct in the context of sexual orientation. The Trust Inventory (TI; Dunn \& Schweitzer, 2005) used in the current study may have been too general to measure the nuance of untrustworthiness historically ascribed to bisexual individuals. The TI measures general trust of others (i.e., "I would expect Adam/Lindsey to pay me back if I loaned him/her \$40.”). Although prior research has suggested that bisexual individuals are considered to be less trustworthy even as friends (Gustavson, 2009; Klesse, 2005; McLean, 2004), it is possible that the TI (Dunn \& Schweitzer, 2005) was unable to capture and measure the aspects of mistrust attributed to bisexual individuals. The mistrust impacting bisexual individuals is related to perceptions of unfaithfulness, promiscuity, tendency to spread STI's, and personal abandonment (Alaire \& Gaudet, 2013; Hequembourg \& Brallier, 2009; Israel \& Mohr, 2004; Klesse, 2005; McLean, 2004; Mohr \& Rochlen, 1999; Spalding \& Peplau, 1997). Perhaps a scale measuring more meaningful and interpersonal levels of trust could capture any differences in populations regarding trustworthiness. Or perhaps a quantitative study or scale cannot capture these stereotypes in the same way qualitative research could. 
Finally, the research questions posed in the current study may have been explored more thoroughly within a qualitative design. As noted previously, in a study by Flanders and Hatfield (2014), quantitative and qualitative results were drastically different and qualitative results illuminate bi-negative beliefs that the quantitative results did not uncover. Perhaps the current variables may be better suited in the future to be explored qualitatively. It may be more useful to understand how these stereotypes are portrayed in bisexual men and women (e.g., performative vs. protective sexual orientations) instead of the "amount" or "level" of trust or stability perceived.

\section{Implications}

Both statistically significant and non-significant findings from the current study provide important implications for counseling psychologists. The non-significant results (i.e., that bisexuality was not considered to be more or less stable depending upon the type of relationship or gender of those in the relationship, and no perceived differences in levels of trust granted to bisexual men and women or bisexual individuals and heterosexual individuals) are encouraging. As noted in the discussion of these findings, this suggests that perceptions and stereotyping of bisexuality may be improving in the heterosexual community. This may provide bisexual clients with greater possibilities and feelings of safety when attempting to connect with others outside of the bisexual community. As noted previously, bisexual individuals have been perceived as untrustworthy not just in romantic relationships (Alaire \& Gaudet, 2013; Hequembourg \& Brallier, 2009; Israel \& Mohr, 2004; Klesse, 2005; McLean, 2004; Mohr \& Rochlen, 1999; Spalding \& Peplau, 1997), but in friendships as well (Gustavson, 2009; Klesse, 2005; McLean, 2004). Because this study did not detect this perception among its participants, it is possible that it may be decreasing, and bisexual individuals may be able to form romantic and platonic relationships easier, leading to fewer feelings of isolation. Because the present study only 
explored heterosexual individuals' perceptions of bisexuality, this possible connection and decreased stereotyping can only be generalized to the heterosexual community. However, although those within the LGBTQ+ community have endorsed biphobic attitudes and behaviors, these have been at much lower levels than those in the heterosexual community (Mohr \& Rochlen, 1999). Therefore, perceptions of bisexuality may also have improved in the overall LGBTQ+ community, which could also possibly result in increased connection with others who identify as non-heterosexual. However, future studies exploring perceptions within the LGBTQ+ community would need to be completed in order to confirm that this trend has continued as this study only explored heterosexual perceptions.

Additionally, although the present study was unable to determine if bisexuality is considered to be a more or less stable sexual orientation than monosexual sexual orientations, the results suggesting that perceptions of stability were not influenced by gender or type of relationship are also encouraging. Again, this may suggest that stereotyping and negative perceptions of bisexuality may be improving, at least in the populations represented in this sample (e.g., those with at least a Bachelor's degree in education in the United States). This is important for counseling psychologists because improved outside perceptions of bisexuality as a stable sexual orientation could possibly lead to decreased feelings of internalized biphobia in bisexual individuals (Burke \& LaFrance, 2018). Bisexual individuals experience internalized biphobia for a myriad of reasons and the perception that their sexual orientation is not legitimate can increase these feelings (Burke \& LaFrance, 2018). Internalized biphobia can lead to several negative health outcomes and decreased wellbeing (Moscardini, Douglass, Conlin, \& Duffy, 2018). The findings from the present study possibly suggesting that perceptions of the stability of bisexuality as a sexual orientation are changing may impact bisexual individuals' own internalized biphobia (if present), which could lead to heightened feelings of security and 
comfort when coming out, which can increase bisexual clients' own wellbeing (Moscardini et al., 2018).

However, as encouraging as the non-significant findings from the current study were, the significant finding suggests less optimistic implications for the bisexual community and counseling psychologists. Although several results in the current study suggest the possibility that stereotyping of bisexuality in the heterosexual community is decreasing, stereotyping of low trustworthiness was possibly activated once a hypothetical heterosexual person was directly impacted by a hypothetical bisexual person. Bisexual men and women in different gender relationships were perceived as less trustworthy than bisexual men and women in same gender relationships. As noted previously, this could be explained by integrated threat theory (Stephan \& Stephan, 2000); the prejudices or stereotypes held by heterosexual participants were only activated once a member of their in group (i.e., other heterosexuals) were threatened, in this case by possible emotional harm.

Therefore, although heterosexual individuals may not endorse the untrustworthy stereotype at face value, when in a romantic relationship with a bisexual person, this stereotype may be activated. Bisexual individuals have reported difficulty dating outside of the bisexual community due to this concern (Bostwick \& Hequembourg, 2014). It is important for counseling psychologists to be aware of this stereotype when working with bisexual clients in romantic relationships with heterosexual individuals and vice versa. The heterosexual partner's mistrust of their bisexual partner could lead to heightened and/or unwarranted feelings of jealousy within the relationship, and in extreme cases possibly intimate partner violence (Tremblay \& Dozois, 2009). This mistrust could also lead to difficulty for heterosexual clients to initiate romantic relationships with bisexual individuals they may be romantically attracted to. It is helpful for 
counseling psychologists to be aware of the low trustworthiness stereotype in order to explore and address these concerns.

Additionally, this perception of low trustworthiness may lead bisexual clients to hide their sexual orientation from romantic partners or others in their lives (Bostwick \& Hequembourg, 2014). Being unable to "come out" and live authentically in their own sexual orientation can lead to negative health and wellness outcomes (Burke \& LaFrance, 2018, Moscardini et al., 2018). Also, just as perceived untrustworthiness of bisexual individuals may make it difficult for heterosexual individuals to initiate romantic relationships with prospective bisexual romantic partners, it may make it difficult for bisexual individuals to initiate relationships with heterosexual partners, limiting the dating pool for bisexual individuals to other bisexual individuals (Bostwick \& Hequembourg, 2014).

Finally, knowledge of this untrustworthy stereotype is particularly important for heterosexual counseling psychologists to be aware of because it may impact their work with bisexual clients. Even if this stereotype is only activated when bisexual clients are in relationships with different gender partners, it could impact heterosexual counseling psychologists' perceptions of their bisexual clients. Mistrust, even mistrust the psychologist is unaware is present, may impact the therapeutic relationship and lead to unwarranted uncertainty or skepticism of bisexual clients' disclosures in session.

\section{Future Directions}

Although the current study only revealed one significant finding, both the significant and non-significant results provide areas of further exploration in future research. In terms of the significant result, future research should address perceptions of individuals in same or different gender relationships. In the current study, bisexual individuals in different gender relationships were perceived to be less trustworthy than those in same gender relationships. Further research 
examining other factors impacting this perception and facets of the construct of trust in terms of its perception of those in same or different gender relationships could be further explored. Additionally, the impact of this perception of trust on bisexual individuals should be explored further.

Additionally, future research may benefit from exploring these questions within specific populations. For example, the majority of participants in the current study reported earning at least a Bachelor's degree. Future research could explore differences in perceptions based on education level, rural/urban location, age, etc.

Furthermore, the current finding that bisexual individuals were considered to be as trustworthy as heterosexual individuals and that bisexual women and men were perceived similarly differs from past research (Alaire \& Gaudet, 2013; Eliason, 2001; Hequembourg \& Brallier, 2009; Herek, 2000; Klesse, 2005; McLean, 2004; Mohr \& Rochlen, 1999; Spalding \& Peplau, 1997; Steffans \& Wagner, 2004; Yost \& Thomas, 2012; Zivony \& Lobel, 2014) and should be explored further.

Future research into trust of bisexual individuals would be aided by a scale designed to specifically measure this construct in terms of bisexuality. The Trust Inventory (Dunn \& Schweitzer, 2005), was not created for this purpose and, while effective at measuring general trustworthiness, is unable to measure criteria and reported beliefs specific to bisexual individuals. As the Attitudes Regarding Bisexuality Scale (Mohr \& Rochlen, 1999) was designed to measure endorsement of attitudes regarding bisexuality as a tolerable and stable sexual orientation, a scale measuring endorsement of attitudes regarding bisexuals as trustworthy is needed to expand the current research.

Additionally, although the ARBS-M/F (Mohr \& Rochlen, 1999) measures perceptions of stability of bisexual men and women, the scale is unable to compare heterosexual and bisexual 
populations. An adaptation of the ARBS-M/F to replace 'bisexuality' with 'heterosexuality' throughout the scale so it can be used to compare bisexual and heterosexual populations may be useful for future research.

Finally, more qualitative research in this area may be able to explore these constructs and research questions in more depth and with more nuance. Using qualitative research methods, participants could openly share their thoughts, perceptions, and attitudes without being provided limited response options. Additionally, researchers could further explore responses provided by participants to understand thought processes and origins of perceptions of bisexual individuals. 


\section{REFERENCES}

Alaire, M., \& Gaudet, S. (2013). I don't know if she is bisexual or if she just wants to get attention": Analyzing the various mechanisms through which emerging adults invisibilize bisexuality. Journal of Bisexuality, 13, 191-214. doi: 10.1080/15299710802171308

American Psychological Association [APA]. (2008). Answers to your questions: For a better understanding of sexual orientation and homosexuality. Washington, DC: Author. Retrieved from www.apa.org/topics/sorientation.pdf

American Psychological Association [APA]. (2012). Guidelines for psychological practice with gay, lesbian, and bisexual clients. American Psychologist, 67(1), 10-42. doi: $10.1037 \mathrm{a} 0024659$

Anderson, E. (2005). In the game: Gay athletes and the cult of masculinity. New York, NY: State University of New York Press.

Anderson, E. (2008). "Being masculine is not about who you sleep with...”: Heterosexual athletes contesting masculinity and the one-time rule of homosexuality. Sex Roles, 58(2), 104-115. doi: 10.1007/s11199-007-9337-7

Anderson, E., \& Adams, A. (2011). “Aren't we all a little bisexual?”: The recognition of bisexuality in an unlikely place. Journal of Bisexuality, 11(1), 3-22. doi: $10.1080 / 15299716.2011 .545283$

Andre, A., Brown, J., Delpercio, A., Kahn, E., Nicoll, A., Sherouse, B. (2014). Supporting and caring for our bisexual youth. Washington, DC: The Human Rights Campaign Foundation.

Ard, K. L., \& Makadon, H. J. (2012). Improving the health care of lesbian, gay, bisexual and transgender (LGBT) people: Understanding and eliminating health disparities [PDF]. 
Retrieved from https://www.lgbthealtheducation.org/wp-content/uploads/Improving-theHealth-of-LGBT-People.pdf

Armstrong, H. L., \& Reissing, E. D. (2014). Attitudes toward casual sex, dating, and committed relationships with bisexual partners. Journal of Bisexuality, 14, 236-264. doi: $10.1080 / 15299716.2014 .902784$

Balsam, K. F., \& Mohr, J. J. (2007). Adaptation to sexual orientation stigma: A comparison of bisexual and lesbian/gay adults. Journal of Counseling Psychology, 54(3), 306-319. doi: 10.1037/0022-0167.54.3.306

Barker, M., \& Landridge, D. (2008). II. Bisexuality: Working with a silenced sexuality. Feminism \& Psychology, 18(3), 389-394. doi: 10.1177/0959353508092093

Barker, M., Richards, C., Jones, R., Bowes-Catton, H., Plowman, T., Yockney, J., \& Morgan, M. (2012). The bisexuality report: Bisexual inclusion in LGBT equality and diversity. Milton Keynes, UK: Centre for Citizenship, Identity and Governance, The Open University.

Blumstein, P.W., \& Schwartz, P. (1974). Lesbianism and bisexuality. In E. Goode (Ed.) Sexual deviance and sexual deviants (pp. 278-295). New York: Morrow.

Bostwick, W., \& Hequembourg, A. (2014). 'Just a little hint': Bisexual-specific microaggressions and their connection to epistemic injustices. Culture, Health \& Sexuality, 16(5), 488-503. doi: 10.1080/13691058.2014.889754

Bowes-Catton, H. (2007). Resisting the binary: Discourses of identity and diversity in bisexual politics 1988-1996. Lesbian \& Gay Psychology Review, 8(1), 58-70.

Bowes-Catton, H., \& Hayfield, N. (2015). Bisexualities. In C. Richards \& M. Barker (Eds.), The Palgrave handbook of the psychology of sexuality and gender (pp. 42-59). London: Palgrave MacMillan. 
Boyer, C. R., \& Galupo, M. P. (2015). Attitudes toward individuals in same-sex and cross-sex encounters: Implications for bisexuality. Journal of Bisexuality, 15, 57-68. doi: $10.1080 / 15299716.2014 .984371$

Breno, A. L., \& Galupo, M. P. (2008). Bias toward bisexual women and men in a marriagematching task. Journal of Bisexuality, 7, 217-235. doi: 10.1080/15299710802171308

Brewster, M. E., \& Moradi, B. (2010). Perceived experiences of anti-bisexual prejudice: Instrument development and evaluation. Journal of Counseling Psychology, 57(4), 451468. doi: 10.1037/a0021116

Brooks, D. (2012). The sampling distribution and central limit theorem. Kirkland, WA: CreateSpace Independent Publishing Platform.

Burke, S. E., \& LaFrance, M. (2018). Perceptions of instability and choice across sexual orientation groups. Group Processes \& Intergroup Relations, 21(2), 257-279. doi: $10.1177 / 1368430216663019$

Clay, R. A. (2010, September). How do I become culturally competent? gradPSYCH, 8(3), 24.

Cochran, S. D., Sullivan, J. G., \& Mays, V. M. (2003). Prevalence of mental disorders, psychological distress, and mental health services use among lesbian, gay, and bisexual adults in the United States. Journal of Consulting and Clinical Psychology, 71(1), 53-61. doi: 10.1037/0022-006x.71.1.53

College Equality Index (n.d.) Retrieved February 22, 2019, from http://www.collegeequalityindex.org/list-colleges-lgbt-center

Condon, C. E., Ritchie, T. D., \& Igou, E. R. (2015). How dyads reminiscence moderates the relations between familiarity, trust, and memory conformity. Social Psychology, 46(2), 65-75. doi: 10.1027/1864-9335/a000222 
Copen, C. E., Chandra, A., \& Febo-Vazquez, I. (2016). Sexual behavior, sexual attraction, and sexual orientation among adults aged 18-44 in the United States: Data from the 20112013 National Survey of Family Growth. National Health Statistics Report, 88, 1-14. doi: 10.1007/978-94-007-5512-3_4

Cormier, E. (2019, February 3). The rapid evolution of queer language [Blog post]. Retrieved from https://cupola.gettysburg.edu/cgi/viewcontent.cgi?article=1344\&context=surge

Couch, L. L., Adams, J. M., \& Jones, W. H. (1996). The assessment of trust orientation. Journal of Personality Assessment, 67(2), 305-323. doi: 10.1207/s15327752jpa6702_7

Cummings, L. L., \& Bromily, P. (1996). The occupational trust inventory (OTI): Development and validation. In R. Kramer \& T. Tyler (Eds.), Trust in organizations: Frontiers of theory and research (pp. 302-330). Thousand Oaks: CA: Sage.

DeVellis, R. F. (2003). Scale development: Theory and application (2nd ed.). Thousand Oaks, CA: Sage Publications.

Diamond, L. (2005). "I'm straight, but I kissed a girl”: The trouble with American media representations of female-female sexuality. Feminism \& Psychology, 15(1), 104-110. doi: $10.1177 / 0959353505049712$

Dunn, J.R., \& Schweitzer, M.E. (2005). Feeling and believing: The influence of emotion on trust. Journal of Personality and Social Psychology, 88(5), 736-748. doi: 10.1037/00223514.88.5.736

Dyar, C., Lytle, A., London, B., \& Levy, S. R. (2017). An experimental investigation of the application of binegative stereotypes. Psychology of Sexual Orientation and Gender Diversity, 4(3), 314-327. doi: 10.1037/sgd0000234

Eliason, M. J. (1997). The prevalence and nature of biphobia in heterosexual undergraduate students. Archives of Sexual Behavior, 26, 317-326. doi: 10.1023/A:1024527032040 
Eliason, M. J. (2001). Bi-negativity: The stigma facing bisexual men. Journal of Bisexuality, 1, 137-154. doi: 10.1300/J159v01n02_05

Eliason, M. J., \& Raheim, S. (1996). Categorical measurement of attitudes about lesbian, gay, and bisexual people. Gay Lesbian Social Services, 4(3), 51-65. doi: 10.1300/j041v04n03_03

Esterline, K., \& Galupo, M. P. (2013). “Drunken curiosity” and "gay chicken”: Gender differences in same-sex performativity. Journal of Bisexuality, 13, 106-121. doi: $10.1080 / 15299716.2013 .755732$

Fahs, B. (2009). Compulsory bisexuality? The challenges of modern sexual fluidity. Journal of Bisexuality, 9, 431-449. doi: 10.1080/15299710903316661

Faul, F., Erdfelder, E., Lang, A. G., \& Buchner, A. (2007). G*Power 3: A flexible statistical power analysis program for the social, behavioral, and biomedical sciences. Behavior Research Methods, 39, 175-191. doi: 10.3758/bf03193146

Feinstein, B. A., Dyar, C., Bhatia, V., Latack, J. A., \& Davila, J. (2014). Willingness to engage in romantic and sexual activities with bisexual partners: Gender and sexual orientation differences. Psychology of Sexual Orientation and Gender Diversity, 1, 255-262. doi: $10.1037 / \mathrm{sqd} 0000047$

Feinstein, B. A., Dyar, C., Bhatia, V., Latack, J. A., \& Davila, J. (2016). Conservative beliefs, attitudes toward bisexuality, and willingness to engage in romantic and sexual activities with a bisexual partner. Archives of Sexual Behavior, 45, 1535-1550. doi: 10.1007/s10508 015-0642-X

Fingerhut, A. W. (2011). Straight allies: What predicts heterosexuals' alliance with the LGBT community? Journal of Applied Social Psychology, 41(9), 2230-2248. doi: 10.1111/j.1559-1816.2011.00807.x 
Flanders, C. E., \& Hatfield, E. (2014). Social perception of bisexuality. Psychology and Sexuality, 5(3), 232-246. doi: 10.1080/19419899.2012.749505

Freud, S. (1905/1963). Three essays on the theory of sexuality. New York: Basic Books.

Galupo, M. P., Ramirez, J. L., \& Pulice-Farrow, L. (2017). “Regardless of their gender”: Descriptions of sexual identity among bisexual, pansexual, and queer identified individuals. Journal of Bisexuality, 17(1), 108-124. doi:

$10.1080 / 15299716.2016 .1228491$

George, S. (1993). Women and bisexuality. London, UK: Scarlet Press.

Gino, F., \& Schweitzer, M. E. (2008). Blinded by anger or feeling the love: How emotions influence advice taking. Journal of Applied Psychology, 93(5), 1165-1173. doi: 10.1037/0021-9010.93.5.1165

Glass, G. V., Peckham, P. D., \& Sanders, J. R. (1972). Consequences of failure to meet assumptions underlying the fixed effects analyses of variance and covariance. Review of Educational Research, 42(3), 237-288. doi: 10.3102/00346543042003237

Guo, J. (2012). Optimal sample size planning for the Wilcoxon-Mann-Whitney and van Elteren tests under cost constraints. Journal of Applied Statistics, 39, 2153-2164. doi: $10.1080 / 02664763.2012 .702265$

Gustavson, M. (2009). Bisexuals in relationships: Uncoupling intimacy from gender ontology. Journal of Bisexuality, 9, 407-429. doi: 10.1080/15299710903316653

Hequembourg, A. L., \& Brallier, S. A. (2009). An exploration of sexual minority stress across the lines of gender and sexual identity. Journal of Homosexuality, 56, 273-298. doi: $10.1080 / 00918360902728517$ 
Herek, G. M. (2000). Sexual prejudice and gender: Do heterosexuals' attitudes toward lesbians and gay men differ? Journal of Social Issues, 56, 251-266. doi: 10.1111/00224537.00164

Herek, G. M. (2002). Heterosexuals' attitudes toward bisexual men and women in the United States. Journal of Sex Research, 39, 264-274. doi: 10.1080/00224490209552150

Huff, C., \& Tingley, D. (2015). “Who are these people?” Evaluating the demographic characteristics and political preferences of MTurk survey respondents. Research and Politics, 2(3), 1-11. doi: 10.1177/2053168015604648

IBM Corp. Released 2016. IBM SPSS Statistics for Macintosh, Version 24.0 [Computer Software]. Armonk, NY: IBM Corp.

Israel, T., \& Mohr, J. (2004). Attitudes toward bisexual women and men: Current research, future directions. Journal of Bisexuality, 4(1/2), 117-134. doi: 10.1300/J159v04n01_09

Jann, B., Jerke, J., \& Krumpal, I. (2012). Asking sensitive questions using the crosswise model: An experimental survey measuring plagiarism. Public Opinion Quarterly, 76(1), 32-49. doi:10.1093/poq/nfr036

Jenefsky, C., \& Miller, D. (1998). Phallic intrusion: Girl-girl sex in Penthouse. Women's Studies International Forum, 21(4), 375-385. doi: 10.1016/S0277-5395(98)00042-9

Johnson-George, C., \& Swap, W. C. (1982). Measurement of specific interpersonal trust: Construction and validation of a scale to assess trust in a specific other. Journal of Personality and Social Psychology, 43(6), 1306-1317. doi: 10.1037/0022-3514.43.6.1306

Jones, K. N., \& Brewster, M. E. (2017). From awareness to action: Examining predictors of lesbian, gay, bisexual, and transgender (LGBT) activism for heterosexual people. American Journal of Orthopsychiatry, 87(6), 680-689. doi: 10.1037/ort0000219 
Jurgens, J. C., Schwitzer, A. M., \& Middleton, T. (2004). Examining attitudes toward college students with minority sexual orientations: Findings and suggestions. Journal of College Student Psychotherapy, 19(1), 57-75. doi: 10.1300/J035v19n01_07

Kohr, R. L., \& Games, P. A. (1974). Robustness of the analysis of variance, the Welch procedure and a box procedure to heterogeneous variances. The Journal of Experimental Education, 43(1), 61-69. doi: 10.1080/00220973.1974.10806305

Klein, F. (1993). The bisexual option ( $2^{\text {nd }}$ ed.). Binghamton, NY: Haworth Press.

Klesse, C. (2005). Bisexual women, non-monogamy and differentialist anti-promiscuity discourses. Sexualities, 8, 445-464. doi: 10.1177/1363460705056620

Kwon, P., \& Hugelshofer, D. S. (2012). Lesbian, gay, and bisexual speaker panels lead to attitude change among heterosexual college students. Journal of Gay \& Lesbian Social Services, 24(1). doi: 10.1080/10538720.2012.643285

Lannutti, P. J., \& Denes, A. (2012). A kiss is just a kiss?: Comparing perceptions related to female-female and female-male kissing in a college social situation. Journal of Bisexuality, 12, 49-62. doi: 10.1080/15299716.2012.645716

Lount, R. J. (2010). The impact of positive mood on trust in interpersonal and intergroup interactions. Journal of Personality and Social Psychology, 98(3), 420-433. doi: $10.1037 / \mathrm{a} 0017344$

Lumley, T., Diehr, P., Emerson, S., \& Chen, L. (2002). The importance of the normality assumption in large public health data sets. Annual Review of Public Health, 23, 151-169. doi: 10.1146/annurev.publheath.23.100901.140546

Lytle, A., Dyar, C., Levy, S. R., \& London, B. (2017). Contact with bisexual individuals reduces binegativity among heterosexuals and lesbians/gay men. European Journal of Social Psychology. Advance online publication. doi: 10/1002/ejsp.2241 
Mays, V. M., \& Cochran, S. D. (2001). Mental health correlates of perceived discrimination among lesbian, gay, and bisexual adults in the United States. American Journal of Public Health, 91(11), 1869-1876. doi: 10.2105/ajph.91.11.1869

Meyers, K. J., Morse, A. J., \& Wheeler, J. A. (2015). When unchecked biases lead to imposition of values: The case for counseling ethics. In Ideas and research you can use: VISTAS 2015. Retrieved from https://www.counseling.org/docs/defaultsource/vistas/article_43955c21f16116603abcacff0000bee5e7.pdf?sfvrsn=b4a412c_8

McLean, K. (2004). Negotiating (non)monogamy: Bisexuality and intimate relationships. Journal of Bisexuality, 4, 83-97. doi: 10.1177/0959353515574786

Meyer, I. (2003). Prejudice, social stress, and mental health in lesbian, gay, and bisexual populations: Conceptual issues and research evidence. Psychological Bulletin, 129(5), 674-697. doi: 10.1037/0033-2909.129.5.674

Mint, P. (2004). The power dynamics of cheating: Effects on polyamory and bisexuality. Journal of Bisexuality, 4, 55-76. doi: 10.1300/J159v04n03_04

Mohr, J. J., Jackson, S. D., Sheets, R. L. (2017). Sexual orientation self-presentation among bisexual-identified women and men: Patterns and predictors. Archives of Sexual Behavior, 46 (7), 1465-1479. doi:10.1007/s10508-016-0808-1

Mohr, J. J., \& Rochlen, A. B. (1999). Measuring attitudes toward bisexuality in lesbian, gay male, and heterosexual populations. Journal of Counseling Psychology, 46(3), 353-369. doi: $10.1037 / 0022-0167.463 .353$

Morales Knight, L. F., \& Hope, D. A. (2012). Correlates of same-sex attractions and behaviors among self-identified heterosexual university students. Archives of Sexual Behavior, 41(5), 1199-1208. doi: 10.1007/s10508-012-9927-5 
Moscardini, E. H., Douglass, R. P., Conlin, S. E., \& Duffy, R. D. (2018). Minority stress and life meaning among bisexual adults: The role of religiosity. Psychology of Sexual Orientation and Gender Diversity, 5(2), 194-203. doi: 10.1037/sgd0000284

Mulick, P. S., \& Wright, L. W., Jr. (2002). Examining the existence of biphobia in the heterosexual and homosexual populations. Journal of Bisexuality, 2, 45-64. doi: 10.1300/J159v02n04_03

Ochs, R. (1990). Gay liberation is our liberation. In T. Geller (Ed.), Bisexuality: A reader and sourcebook (p. 2). Ojai, CA: Times Change.

Paolacci, G., Chandler, J., \& Ipeirotis, P.G. (2010). Running experiments on Amazon Mechanical Turk. Judgment and Decision Making, 5(5), 411-419. doi: $10.1145 / 1869086.1869094$

Parents and Friends of Lesbians and Gays (2019). PFLAG national glossary of terms. Retrieved from https://pflag.org/glossary

Pistella, J., Salvati, M., Ioverno, S., Laghi, F., \& Baiocco, R. (2016). Coming-out to family members and internalized sexual stigma in bisexual, lesbian and gay people. Journal of Child and Family Studies, 25(12), 3694-3701. doi: 10.1007/s10826-016-0528-0

Poynter, K. J. (2016). Bisexuality and pansexuality workshop. In K. J. Poynter (Ed.), Safe zones: Training allies of LGBTQIA+ young adults (pp. 43-60). Lanham, MD: Rowman \& Littlefield.

Refinetti, R. (1996). Demonstrating the consequences of violations of assumptions in betweensubjects analysis of variance. Teaching of Psychology, 23(1), 51-54. doi: 10.1207/s15328023top2301_14 
Richardsfink, P. (2014, December 14). Bisexual identity development: Perspectives, similarities, and contrasts. Retrieved from https://fliponymous.wordpress.com/2014/12/14/bisexualidentity-development-perspectives-similarities-and-contrasts/

Ross, L. E., Dobinson, C., \& Eady, A. (2010). Perceived determinants of mental health for bisexual people: A qualitative examination. American Journal of Public Health, 100(3), 496-502. doi: 10.2105/AJPH.2008.156307

Rupp, L. J., \& Taylor, V. (2010). Straight girls kissing. Contexts, 9, 28-32. doi: $10.1525 /$ ctx.2010.9.3.28x

Rust, P. (1993). Neutralizing the political threat of the marginal woman: Lesbians' beliefs about bisexual women. The Journal of Sex Research, 30(3), 214-228. doi: 157.182.221.198

Rust, P. C. (1995). Bisexuality and the challenge to lesbian politics: Sex, loyalty, and revolution. New York, NY: New York University Press.

Rust, P. C. R. (2000). The biology, psychology, sociology, and sexuality of bisexuality. In P. C. R. Rust (Ed.), Bisexuality in the United States: A social science reader (pp. 403-470). New York, NY: Columbia University Press.

Sorrel, L. (2018, April 3). Bisexuality vs. pansexuality. Retrieved from https://outwritenewsmag.org/2018/04/bisexuality-vs-pansexuality/

Spalding, L. R., \& Peplau, L. A. (1997). The unfaithful lover: Heterosexuals’ perceptions of bisexuals and their relationships. Psychology of Women Quarterly, 21, 611-625. doi: 10.1111/j.1471-6402.1997.tb00134.x

Steffans, M. C., \& Wagner, C. (2004). Attitudes toward lesbians, gay men, bisexual women, and bisexual men in Germany. Journal of Sex Research, 41, 137-149. doi: $10.1080 / 00224490409552222$ 
Stephan, W. G., \& Stephan, C. W. (2000). An integrated threat theory of prejudice. In S. Oskamp (Ed.), Reducing prejudice and discrimination (pp. 23-45). Mahwah, NJ: Lawrence Erlbaum Associates.

Substance Abuse and Mental Health Services Administration [SAMHSA]. (2014). Culturally responsive evaluation and treatment planning. In Improving cultural competence: Treatment improvement protocol (TIP) (pp. 57-71). Rockville, MD: Substance Abuse and Mental Health Services Administration.

Szymanski, D. M. (2006). Does internalized heterosexism moderate the link between heterosexist events and lesbians’ psychological distress? Sex Roles, 54, 227-234. doi: 10.1007/s11199-006-9340-4

Szymanski, D. M., Kashubeck-West, S., \& Meyer, J. (2008). Internalized heterosexism: Measurement, psychosocial correlates, and research directions. The Counseling Psychologist, 36, 525-574. doi: 10.1177/0011000007309489

Tebbe, E. N., \& Moradi, B. (2012). Anti-transgender prejudice: A structural equation model of associated constructs. Journal of Counseling Psychology, 59(2), 251-261. doi: $10.1037 / \mathrm{a} 0026990$

Tebbe, E. A., Moradi, B., \& Ege, E. (2014). Revised and abbreviated forms of the genderism and transphobia scale: Tools for assessing anti-trans prejudice. Journal of Counseling Psychology, 61(4), 581-592. doi: 10.1037/cou0000043.supp

Tremblay, P. F., \& Dozois, D. A. (2009). Another perspective on trait aggressiveness: Overlap with early maladaptive schemas. Personality and Individual Differences, 46, 569 -574. doi: 10.1016/j.paid.2008.12.009 
Vaughn, L. A., Harkness, A. R., \& Clark, E. K. (2010). The effect of incidental experiences of regulatory fit on trust. Personal Relationships, 17, 57-69. doi: 10.1111/j.14756811.2010.01252.x

Wagaman, M. A. (2016). Self-definition as resistance: Understanding identities among LGBTQ emerging adults. Journal of LGBT Youth, 13(3), 207-230. doi:

$10.1080 / 19361653.2016 .1185760$

Walters, M. L., Chen J., \& Breiding, M. J. (2013). The National Intimate Partner and Sexual Violence Survey (NISVS): 2010 findings on victimization by sexual orientation. Atlanta, GA: National Center for Injury Prevention and Control, Centers for Disease Control and Prevention.

Woodford, M. R., Kulick, A., Sinco, B. R., \& Hong, J. S. (2014). Contemporary heterosexism on campus and psychological distress among LGBQ students: The mediating role of selfacceptance. American Journal of Orthopsychiatry, 84, 519-529. doi: 10.1037/ort0000015

Worthington, R. L., Dillon, F. R., \& Becker-Schutte, A. M. (2005). Development, reliability, and validity of the Lesbian, Gay, and Bisexual Knowledge and Attitudes Scale for Heterosexuals (LGB-KASH). Journal of Counseling Psychology, 52(1), 104-118. doi: $10.1037 / 0022-0167.52 .1 .104$

Yost, M. R., \& Thomas, G. D. (2012). Gender and binegativity: Men's and women's attitudes toward male and female bisexuals. Archives of Sexual Behavior, 41, 691-702. doi: $10.1007 / \mathrm{s} 10508-011-9767-8$

Zivony, A., \& Lobel, T. (2014). The invisible stereotypes of bisexual men. Archives of Sexual Behavior, 43(6), 1165-1176. doi: 10.1007/s10508-014-0263-9 


\section{APPENDICES}

\section{Appendix A: Vignettes}

\section{Condition One Vignette (Heterosexual, Male, Different Gender Relationship)}

Adam and Kate met a year ago when Adam started working at the same office as Kate. At the time, Adam was dating his girlfriend of two years, Julia. However, soon after starting his new job, Adam and Julia broke up. Adam and Kate struck up a close friendship immediately upon meeting and began dating after his breakup. They have now been dating for nine months. Adam identifies as heterosexual and has had several girlfriends in the past, but when asked he always says that Kate is different and that he believes their relationship will last.

\section{Condition Two Vignette (Heterosexual, Female, Different Gender Relationship)}

Lindsey and Erik met a year ago when Lindsey started working at the same office as Erik. At the time, Lindsey was dating her boyfriend of two years, Shawn. However, soon after starting her new job, Lindsey and Shawn broke up. Lindsey and Erik struck up a close friendship immediately upon meeting and began dating after her breakup. They have now been dating for nine months. Lindsey identifies as heterosexual and has had several boyfriends in the past, but when asked she always says that Shawn is different and that she believes their relationship will last.

\section{Condition Three Vignette (Bisexual, Male, Same Gender Relationship)}

Adam and Erik met a year ago when Adam started working at the same office as Erik. At the time, Adam was dating his girlfriend of two years, Julia. However, soon after starting his new job, Adam and Julia broke up. Adam and Erik struck up a close friendship immediately upon meeting and began dating after his breakup. They have now been dating for nine months. Adam identifies as bisexual and has had several girlfriends and boyfriends in the past, but when asked he always says that Erik is different and that he believes their relationship will last. 


\section{Condition Four Vignette (Bisexual, Male, Different Gender Relationship)}

Adam and Kate met a year ago when Adam started working at the same office as Kate. At the time, Adam was dating his boyfriend of two years, Shawn. However, soon after starting his new job, Adam and Shawn broke up. Adam and Kate struck up a close friendship immediately upon meeting and began dating after his breakup. They have now been dating for nine months. Adam identifies as bisexual and has had several girlfriends and boyfriends in the past, but when asked he always says that Kate is different and that he believes their relationship will last.

\section{Condition Five Vignette (Bisexual, Female, Same Gender Relationship)}

Lindsey and Kate met a year ago when Lindsey started working at the same office as Kate. At the time, Lindsey was dating her boyfriend of two years, Shawn. However, soon after starting her new job, Lindsey and Shawn broke up. Lindsey and Kate struck up a close friendship immediately upon meeting and began dating after her breakup. They have now been dating for nine months. Lindsey identifies as bisexual and has had several girlfriends and boyfriends in the past, but when asked she always says that Kate is different and that she believes their relationship will last.

\section{Condition Six Vignette (Bisexual, Female, Different Gender Relationship)}

Lindsey and Erik met a year ago when Lindsey started working at the same office as Erik. At the time, Lindsey was dating her girlfriend of two years, Julia. However, soon after starting her new job, Lindsey and Julia broke up. Lindsey and Erik struck up a close friendship immediately upon meeting and began dating after her breakup. They have now been dating for nine months. Lindsey identifies as bisexual and has had several girlfriends and boyfriends in the past, but when asked she always says that Erik is different and that she believes their relationship will last. 


\section{Appendix B: Manipulation Check}

1. What was the name of the person you just read about?
a. Adam
b. Julia
c. Shawn
d. Lindsey

2. What was the sexual orientation of the person you just read about?
a. Heterosexual
b. Gay
c. Lesbian
d. Bisexual
e. Asexual 


\section{Appendix C: Trust Inventory}

Please consider the person from your vignette. With them in mind, please read each of the following statements and rate them according to how accurately they describe your attitudes and beliefs. Please respond honestly and answer every question according to the rating scale below.

Not At All Likely 1----------2-----------3----------4----------5----------6---------- 7 Very Likely

1. I would give Adam/Lindsey an important letter to mail after $s / h e$ mentions that $s / h e$ is stopping by the post office today.

2. If Adam/Lindsey promised to copy a presentation for me, s/he would follow through.

3. If Adam/Lindsey and I decided to meet for coffee, I would be certain s/he would be there.

4. I would expect Adam/Lindsey to tell me the truth if I asked him/her for feedback on an idea related to my job.

5. If Adam/Lindsey was late to a meeting, I would guess there was a good reason for the delay.

6. Adam/Lindsey would never intentionally misrepresent my point of view to others.

7. I would expect Adam/Lindsey to pay me back if I loaned him/her $\$ 40$.

8. If Adam/Lindsey laughed unexpectedly at something I did or said, I would know s/he was not being unkind.

9. If Adam/Lindsey gave me a compliment on my haircut I would believe s/he meant what was said.

10. If Adam/Lindsey borrowed something of value and returned it broken, s/he would offer to pay for the repairs. 


\section{Appendix D: Attitudes Regarding Bisexuality Scale-Female Version, Stability Subscale}

Please read each of the following statements and rate them according to how accurately they describe your attitudes and beliefs. Please respond honestly and answer every question according to the rating scale below.

Strongly Disagree 1---------------2---------------3---------------4---------------5 Strongly Agree

1. Most women who identify as bisexual have not yet discovered their true sexual orientation.

2. Most women who call themselves bisexual are temporarily experimenting with their sexuality.

3. Female bisexuals are afraid to commit to one lifestyle.

4. Most women who claim to be bisexual are in denial about their true sexual orientation.

5. Lesbians are less confused about their sexuality than bisexual women.

6. Just like homosexuality and heterosexuality, bisexuality is a stable sexual orientation for women. 


\section{Appendix E: Attitudes Regarding Bisexuality Scale-Male Version, Stability Subscale}

Please read each of the following statements and rate them according to how accurately they describe your attitudes and beliefs. Please respond honestly and answer every question according to the rating scale below.

Strongly Disagree 1---------------2---------------3---------------4---------------5 Strongly Agree

1. Most men who claim to be bisexual are in denial about their true sexual orientation.

2. Gay men are less confused about their sexuality than bisexual men.

3. Just like homosexuality and heterosexuality, bisexuality is a stable sexual orientation for men.

4. Most men who identify as bisexual have not yet discovered their true sexual orientation.

5. Most men who call themselves bisexual are temporarily experimenting with their sexuality.

6. Male bisexuals are afraid to commit to one lifestyle. 


\section{Appendix F: Demographics Questionnaire}

Please answer the following questions to the best of your ability.

1. What is your current age?

2. What is your gender identity?
a. Woman
b. Man
c. Trans woman
d. Trans man
e. Genderqueer/Gender non-conforming
f. Different gender (please state)

3. What is your sexual orientation?
a. Heterosexual/Straight
b. Lesbian
c. Gay
d. Bisexual
e. Asexual
f. Questioning/Unsure
g. Different sexual orientation (please state)

4. What is your race/ethnicity?
a. White/Caucasian
b. Black/African-American
c. American Indian/Alaskan Native
d. Asian
e. Native Hawaiian/Pacific Islander
f. Two or more races
g. Latino/a
h. Different race/ethnicity (please state)

5. What is your current relationship status?
a. Single, never married or in domestic/civil partnership
b. Married
c. Separated
d. Divorced
e. Widowed
f. Partnered

6. In what US state or territory do you currently live? 
Drop down box

7. What is your highest completed level of education?
a. High school diploma
b. GED
c. Associate's degree
d. Bachelor's degree
e. Master's degree
f. Doctorate degree
g. Unsure
h. Not listed (please state) 


\section{Appendix G: Informed Consent Form}

\section{Dear Participant,}

This letter is a request for you to take part in a research project to assess perceptions of bisexuality. This project is being conducted by Jeneice Shaw, MA in the Department of Counseling, Rehabilitation Counseling, and Counseling Psychology at WVU with supervision of Dr. Lisa Platt, an assistant professor in the College of Education and Human Services, for a Doctor of Philosophy Degree in Counseling Psychology. Your participation in this project is greatly appreciated and will take approximately 10 to 15 minutes to fill out the attached questionnaire.

Your involvement in this project will be kept as confidential as legally possible. All data will be reported in the aggregate. You must be 18 years of age or older to participate. I will not ask any information that should lead back to your identity as a participant. Your participation is completely voluntary. You may skip any question that you do not wish to answer and you may discontinue at any time. West Virginia University's Institutional Review Board acknowledgement of this project is on file.

I hope that you will participate in this research project, as it could be beneficial in understanding perceptions of bisexuality and its impacts. Thank you very much for your time. Should you have any questions about this letter or the research project, please feel free to contact Jeneice Shaw at (304) 293-3568 or by e-mail at jlshaw @ mix.wvu.edu.

Thank you for your time and help with this project.

Sincerely, Jeneice Shaw, MA 


\section{Appendix H: Debriefing Form}

Thank you for your participation in this study! Your responses to the survey questions are greatly appreciated.

\section{Anonymity and Confidentiality:}

Your responses are completely anonymous as no identifying information has been requested from you. In addition, the secure survey software (Qualtrics) that collected your responses has been programmed to anonymize all data by removing respondents' IP addresses.

In order to maintain the quality of this study, please do not disclose research procedures to anyone who might participate in this study in the future as this could bias the results.

\section{Final Report:}

If you would like to receive a copy of a summary of the findings of this study when it is completed, please feel free to contact me at jlshaw@mix.wvu.edu. 
Appendix I: IRB Approval

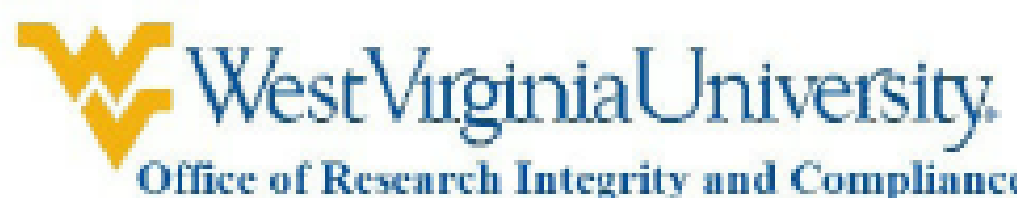

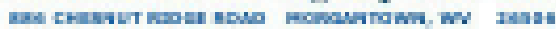

\section{Acknowledgement of Eremption}

$02 / 3 / 2018$

To: Jeneice Shaw

From: WVU Ofice of Research Integiity $\&$ Compliance

Protocol Type: Exempt

Submission Type: Initial

Funding N/A

WVU Protocol \#: 1801954967

Protocol Title: Trustworthiness and Stability in Same and Different Sex Relationships: Heterosexauals' Attitudes toward Bisewality

The Wort Viginia Umivority Intitutional Revien Board has roviawod your submission of Exampt Frotood 1801954967. Additional denils regarding the rwiow are below:

- This rwarch staty was grantad an axamption because the Rowarch imvolves adocational tonts, varvy procatures, intorviow procedurw or obuarvation of public bahnior and (0) information obtaingd in recordad in such a mannar that hmann mbjocts camot be identified, diroctly or through idemtifiar linked to the rubjects; and (ii) any divelonure of the hrman rubjects reponses outside the ronourch could not roasonably place the subjects at risk of criminal or civil liability or be damaging to the rubjocts financial atending, employpbility, or roputation [45 CFR 46.101(2)]. All aremptions are only good for three yours. If this resourch oxtends more than thre years boyond the approvod date, then the rwarcher will hawe to requent another oxamption. The folloring docamonts have beon achnowledged for use in this study and are available in the WVUthe systam:

- For future reforasea: Plasse note that rather tham the confidantiality statament in the cover lattor you could have stated that the stndy is anonymous since you cannot ancartain the participant's identity.

The following docmmants ware roviowed and approwed for use as part of this mulmission. Only the documents listad below may be wed in the renasuch. Plase accoss and print the filos in the Noten $f$ Attachments wetion of your approwed protecol.
There 3+21230

Par 34-21-val

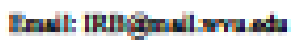


- MTurk Racritmont Taxi pdf

- Coum Lattor paf

- Viguettantaf

- Trust Irventorypdf

- Artituda Rogarting Bisocuality Scalo Famale Vervion.pdf

- Artitada Ragarding Biromality Scala Mala Vorrion.pdf

- Domographica Quontionaira pdf

- Manipulation Chos paf

WVU IRB aclenwledgement of protocol 1801954967 will expire on 02/22021.

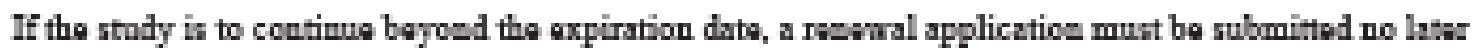
thun two (2) woks prior to expiration date. It in your roponsibility to rubmit your protocol for romowal.

Onca you begin you thman wabjocts ronouch, the following regulations apply:

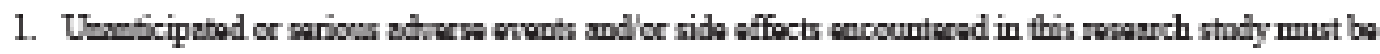
rapotod to the IRB within fro (S) dys, uring to Notify IIB action in the olactronic protocol.

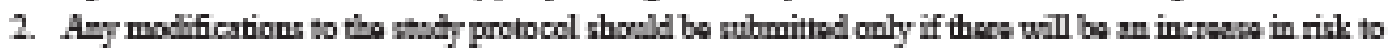

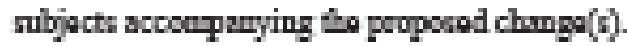

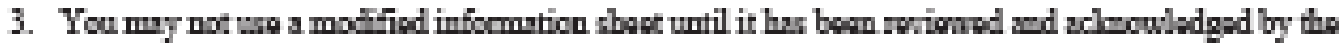
WU IRB prim to implanoctation.

The Office of Rosomch Integrity and Complianes will be glad to provide assistance to you throughout

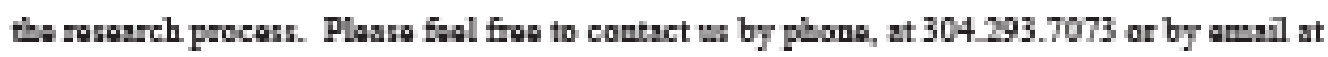
IFFingail womatu.

Sinceraly:

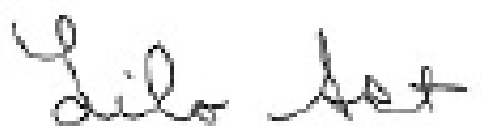

Lilo Ast

Stnior Program Coondinator 
CURRICULUM VITAE

JENEICE SHAW, M.A.

Address: 512 Timberline

Morgantown, WV 26505

Phone: 240-625-2508

Email: jlshaw@mail.wvu.edu

\section{$\underline{\text { EDUCATION }}$}

Ph.D. Counseling Psychology, West Virginia University (APA accredited), In Progress, GPA = 4.0, Dissertation proposal completed September 25, 2017, Dissertation defense anticipated March 2019

M. A. Counseling, Ball State University (APA Accredited), July 2013, GPA = 3.9

B. A.

Psychology and Gender Studies, McDaniel College, May 2011, GPA $=3.9$, summa cum laude with Departmental Honors

\section{COLLEGE COUNSELING CENTER EXPERIENCE}

Doctoral Intern (July 2018-Present)

West Virginia University Carruth Center for Psychological and Psychiatric Services, Morgantown, WV

- Individual Therapy: Maintain caseload of between 10-15 individual clients. Engage in brief therapy. Facilitate appropriate referrals and continuity of care (e.g., medication referrals and referrals to psychologists in the Morgantown community appropriate for clients in need of long-term care). Complete all progress notes and associated paperwork in a timely manner.

- Group Therapy: Co-facilitate a Graduate Student Women's process group and LGBTQ+ support group for 3 hours total weekly. Engaged in pre-group interviews, collaboratively made decisions about group fit, attend group supervision following each group session, and complete associated group paperwork.

- Initial assessments: Responsible for 1-2 weekly initial assessment appointments. Communicate all treatment recommendations and referrals to clients and complete all associated paperwork within 24 hours.

- Crisis and Consultation: Available for weekly drop in appointments including crises as well as in-person and over-the-phone consultations for students, students' families, faculty, and staff. Responsible on rotating basis for responding to after hour calls from students in crisis.

- Supervision: Engage in 3 hours of individual supervision as well as provide 1 hour of supervision to a doctoral trainee weekly.

- Outreach: Engage in didactic and interactive outreach programming. Respond to campus outreach requests and create original material. Act as liaison between the Carruth Center and the LGBTQ+ Center. Participate as a leadWELL trainer and train two groups of undergraduate students to notice when another peer is struggling emotionally or academically and how to best assist them. Liaison between the Carruth Center and a residence hall on campus.

- Psychological Assessment: Complete learning disability and ADHD assessments with students seeking academic accommodations. Responsible for completing integrated reports 
explaining results and providing feedback to students. Administer the D-KEFS, IVA-2, NVMSVT, WAIS-IV, WASI-II, and WJ-IV.

- Committees: Member of Outreach Committee. Assisted in developing outreach requirements for trainees as well as new outreach procedures.

- Special Emphasis: Special emphasis on working with students within the LGBTQ+ community. Co-lead LGBTQ+ support group, act as a liaison between the Carruth Center and WVU's LGBTQ+ Center, work with several clients individually who identify within the LGBTQ+ community and who have presenting concerns related to this identity, and trained to provide Safe Zone trainings on campus. Responsible for creating a leadWELL group within the LGBTQ+ Center as well as outreach events for LGBTQ+ students and allies.

Licensed Individual Supervisors: Matthew Kellar, Psy.D. (Spring 2019); T. Anne Hawkins, Ph.D. (Spring 2019); Tandy McClung, Ed.D (Fall 2018); Al Kasprowicz, Ph.D. (Fall 2018) Group Supervisors/Co-facilitators: Christine Simpson, Psy.D., T. Anne Hawkins, Ph.D., Stephanie Harrison, Psy.D.

Training Director: Shane Chaplin, Ph.D.

Practicum Therapist (August 2015 - May 2018)

West Virginia University Carruth Center for Psychological and Psychiatric Services, Morgantown, WV

- Individual Therapy: Maintained caseload of approximately 15 individual clients. Engaged in brief therapy. Facilitated appropriate referrals and continuity of care (e.g., medication referrals and referrals to psychologists in the Morgantown community appropriate for clients in need of long-term care). Completed all progress notes and associated paperwork in a timely manner.

- Group Therapy: Facilitated a drop in, psychoeducation group for 1 hour weekly. Cofacilitated a Women's Empowerment group for 1.5 hours weekly. Engaged in pre-group interviews, collaboratively made decisions about group fit, attended group supervision before each group session, and completed associated group paperwork.

- Initial assessments: Responsible for 1-2 weekly initial assessment appointments. Communicated all treatment recommendations and referrals to clients and completed all associated paperwork within 24 hours.

- Crisis and Consultation: Was available for weekly drop in appointments including crises as well as in-person and over-the-phone consultations for students, students' families, faculty, and staff.

- Supervision: Engaged in 2 hours of individual supervision and 1.5 hours of group supervision weekly.

- Outreach: Engaged in didactic and interactive outreach programming. Presented on topics including healthy relationships, sexual health, consent, and stress management. Responded to campus outreach requests and created original material. Acted as liaison between the Carruth Center and the Office of Wellness and Health Promotion to collaborate on outreach as needed. Organized Wellness Workshop Series.

- Psychological Assessment: Completed learning disability and ADHD assessments with students seeking academic accommodations. Was responsible for completing integrated reports explaining results and providing feedback to students. Administered the D-KEFS, IVA-2, NV-MSVT, WAIS-IV, WJ-IV, and WRAT4. 
Licensed Individual Supervisors: Shane Chaplin, Ph.D. (Fall 2015, Summer 2016); Tandy

McClung, Ed.D. (Spring 2016); Mei Ng, Ph.D. (Fall 2016); Narayan Gold, Ph.D. (Spring 2017);

Ashley Kasardo, Psy.D. (Summer 2017); T. Anne Hawkins, Ph.D. (Fall 2017); Teresa Stire,

Ph.D. (Fall 2017)

Group Supervisor/Co-facilitator: Ashley Kasardo, Psy.D.

Training Director: Shane Chaplin, Ph.D.

Practicum Therapist (August 2012 - May 2013)

Counseling Center, Ball State University, Muncie, IN

- Maintained a caseload of 12-15 individual clients. Provided time-limited counseling.

- Process observed an interpersonal process group for 1 hour weekly (Fall 2012). Cofacilitated an interpersonal process group for 1 hour weekly (Spring 2013). Co-facilitated an international student drop in group for 1 hour weekly (Spring 2013).

- Engaged in 1-2 weekly intake interviews, provided disposition, and completed all associated paperwork.

- Facilitated psychiatric referrals as necessary.

- Engaged in outreach programming, including body image, eating disorder, and sexual assault programs. Served as a team member for both the Sexual Threats Oppression Prevention (STOP) Team and the Eating Disorder Awareness Team.

- Attended 1 hour of individual supervision and 1 hour of group supervision weekly.

- Participated in a weekly diversity seminar.

Individual Supervisor: Tzu-An Hu, Ph.D.

Group Supervisors: Kyle Kittleson, Psy.D.; Pei-Yi Lin, Ph.D.

\section{RELEVANT CLINICAL EXPERIENCE}

Practicum Therapist (January 2012 - July 2012)

Ball State Counseling Practicum Clinic, Muncie, IN

- Engaged in psychotherapy with adults. Clients were largely of lower SES.

- Conceptualized and created treatment plans.

- Scheduled clients and completed all associated paperwork.

- Participated in 1 hour of individual supervision provided by a doctoral student and 1.5 hours of group supervision provided by a licensed psychologist weekly.

- Co-facilitated a distress management group for kindergarten and first grade children diagnosed with developmental or behavioral disorders 4 hours monthly (Spring 2012).

Supervisors: Yui Chung Chan, Ph.D. (Spring 2012); Theresa Kruczek, Ph.D. (Summer 2012)

\section{RELEVANT WORK EXPERIENCE}

Graduate Assistant (July 2016 - July 2018)

Office of Wellness and Health Promotion, Morgantown, WV

- Planned and coordinated wellness events for West Virginia University students.

- Facilitated outreaches on sexual health, consent, mindfulness, and relaxation techniques.

- Developed original programs and interactive games to facilitate education. 
- Assisted with weekly Student Wellness Ambassador Team meetings.

- Trained graduate student trainers participating in the leadWELL program as well as assisted in scheduling and coordinating training with undergraduate student mentors.

- Was responsible for condom and dental dam inventory and purchasing.

- Acted as a liaison for the Carruth Center for Psychological and Psychiatric Services.

- Supervised undergraduate interns.

Supervisor: Shannon Foster, M.S.

Intern and Hotline Volunteer (January 2011 - May 2011)

Rape Crisis Intervention Services of Carroll County, Westminster, MD

- Acted as a liaison between the center and local college (McDaniel College).

- Assisted in scheduling and planning events in the community.

- Participated in advocacy work.

- Analyzed data relating to services used by the community.

- Trained to respond to the emergency hotline and accompany sexual assault survivors to the emergency department.

Supervisor: Sarah Brown, M.A.

Intern (May 2010 - August 2010)

Mental Health Association of Franklin and Fulton Counties, Chambersburg, PA

- Entered and analyzed data.

- Assisted in scheduling and planning events in the community.

- Shadowed counselors on peer-to-peer visits.

Supervisor: Kenneth Wuertenberg

\section{RESEARCH EXPERIENCE}

Research Assistant (August 2015 - May 2016)

Department of Counseling, Rehabilitation Counseling, and Counseling Psychology, West

Virginia University, Morgantown, WV

- Assisted with a professional competencies project. Performed literature searches and reviews and compiled data and reports.

- Contacted possible participants.

- Assisted in creating surveys in Qualtrics.

Supervisor: Jennifer Taylor, Ph.D.

\section{TEACHING EXPERIENCE}

Teaching Assistant (August 2014 - August 2015)

Courses: Diversity and Human Relations, Career and Lifespan Development, Interpersonal Communication Skills, Introduction to the Helping Profession 
Department of Counseling, Rehabilitation Counseling, and Counseling Psychology, West

Virginia University, Morgantown, WV

- Held weekly office hours.

- Graded examinations, papers, and homework assignments within set deadlines.

- Facilitated online discussions on class materials.

Supervisor: Jeff Daniels, Ph.D.

Writing Fellow (August 2010 - December 2010)

Course: Writing in Psychology

Department of Psychology, McDaniel College, Westminster, MD

- Met individually with students before major assignments.

- Facilitated APA writing workshops.

- Provided feedback on drafts of assignments.

Supervisor: Wendy Morris, Ph.D.

Teaching Assistant/Tutor (January 2010 - May 2010)

Course: Psychology Methods and Statistics II

Department of Psychology, McDaniel College, Westminster, MD

- Met individually with students upon request.

- Held review sessions before exams and major assignments.

Supervisor: Madeline Rhodes, Ph.D.

Tutor (August 2009 - December 2009)

Course: Psychology Methods and Statistics I

Department of Psychology, McDaniel College, Westminster, MD

- Worked one-on-one with two students with learning disabilities and hearing impairments.

- Met weekly with each student for 1-3 hours to review homework, new lessons, and to study for upcoming exams.

Supervisor: Madeline Rhodes, Ph.D.

\section{PUBLICATIONS AND PRESENTATIONS}

Shaw, J. (2017, April 4). Heterosexuals' perceptions of bisexuals' stability and trustworthiness in same and different sex relationships. Poster presented at West Virginia University, College of Education and Human Services' Student Research Forum, Morgantown, West Virginia.

Shaw, J., Latorre, C., Scott, O., \& Daniels, J. (2017, April 1). Ambushes and unprovoked attacks against law enforcement: A final report. Poster presented at Great Lakes Regional Counseling Psychology Conference, Muncie, Indiana.

Scott, O., Shaw, J., \& Berkey, S. (2016, April 9). Speaking out for Syrian refugees: A creative appeal to the governor of Indiana. Social justice project conducted at Great Lakes Regional Counseling Psychology Conference, Bloomington, Indiana. 
Shaw, J., Shannon, B., Scott, O., \& Latorre, C. (2016, April 8). Campus to community: Speak out, reach out. Poster presented at Great Lakes Regional Counseling Psychology Conference, Bloomington, Indiana.

Shannon, B., \& Shaw, J. (2016, April 8). Shedding light on religious privilege. Poster presented at Great Lakes Regional Counseling Psychology Conference, Bloomington, Indiana.

Shaw, J. (Chair) (2016, April 8). Demystifying Human Trafficking in the United States. Lecture conducted at Great Lakes Regional Counseling Psychology Conference, Bloomington, Indiana.

Shaw, J. (2016, April 5). Respect, understanding, and awareness: Working with transgender clients. Poster presented at West Virginia University, College of Education and Human Services' Student Research Forum, Morgantown, West Virginia.

Shaw, J. L. A., Shannon, B. J., Greenbaum, H., \& Taylor, J. (2015). From college to community: Speak Out, Reach Out. In M.G. Hickey (Ed.), Reflecting on Service Learning in Higher Education (189-196). Lexington Books: Lanham, Maryland.

Daniels, J. (Director) (2015, August 8). Law Enforcement Officer Ambushes: The Psychology of Officers and Offenders. American Psychological Association Annual Conference. Lecture conducted from American Psychological Association, Toronto.

Greenbaum, H., Webb, B., Scott, O., Shaw, J., Shannon, B., \& Taylor, J. (2015, October). Speak out reach out (SORO): Student-led group affirming diversity at WVU and in our local community. Poster presented at West Virginia Psychological Association Conference, Morgantown, West Virginia.

Niegocki, K., Aegisdottir, S., Mitchell, A. M., Shaw, J., Curtis, S., Trotter, B., \& Gotschall, B. (2014, August). College women's experiences of sexual coercion: A qualitative study. Poster presented at the Annual Meeting of the American Psychological Association, Washington, DC.

Shaw, J. (2012). Perceived susceptibility to negative consequences of risky sexual behavior among college students (Unpublished master's thesis). Ball State University, Muncie, Indiana.

Yakunina, E., Snyder, E., Adams, D., Hall, D., Howell, D., Niegocki, K., Terhune, J. \& Shaw, J. (2012, February).The college student power and control wheel. Poster session presented at Big 10 Counseling Center Conference 2012: Social Media, Human Connections, Mental Health: It's Complicated, Bloomington, Indiana.

Shaw, J. (2012, April). Effect of gender, perceived consent, and level of homophobia on perceptions of sexual assault survivors. Poster presented at the Great Lakes Regional Counseling Psychology Conference, Lafayette, Indiana.

Shaw, J. (2011). Effect of gender, perceived consent, and level of homophobia on perceptions of sexual assault survivors (Unpublished undergraduate capstone). McDaniel College, Westminster, Maryland.

Shaw, J. (2010, November). Wearing white on the beach? I must be on my period. Paper presented at the Mid Atlantic Popular and American Culture Conference, Alexandria, Virginia

\section{MANUSCRIPTS IN PROGRESS}

Platt, L., \& Shaw, J. (2019). All shades of the gender rainbow: Considerations for gender diverse girls and youth. In V. Bwallah-Swaray, W.S. Williams, \& B. Garrett-Akinsanya (Eds.), Girls Like Us. 


\section{$\underline{\text { PROFESSIONAL MEMBERSHIPS }}$}

Member, American Psychological Association (December 2014 - present)

APA Division 17, Society of Counseling Psychology

\section{PROFESSIONAL DEVELOPMENT ACTIVITIES}

West Virginia University Policy Safe Zone Training (September 2018)

West Virginia University Safe Zone Training (March 2017)

Regional Coordinator and West Virginia University Program Representative, Student

Affiliates of Seventeen, Society of Counseling Psychology (January 2015-August 2016)

Secretary and Founding Member, Speak Out Reach Out (August 2014-May 2016)

Ball State University Trans Safe Zone Training (October 2013)

Ball State University Safe Zone Training (March 2012)

\section{$\underline{\text { HONORS AND AWARDS }}$}

Berlin B. Chapman Graduate Student Award, West Virginia University (May 2017)

Best Oral Presentation of Poster, College of Education and Human Services Research Forum, West Virginia University (April 2016)

Mary Ward Lewis Award, McDaniel College (May 2011)

Malcom L. Meltzer Psychology Award, McDaniel College (May 2011)

Member of Phi Beta Kappa (Academic Honor Society) (May 2011)

Student Research and Creativity Grant, McDaniel College (August 2010)

Member of Psi Chi (National Honor Society in Psychology) (November 2008)

Dean's Honor List at McDaniel College (2007-2011)

\section{$\underline{\text { REFERENCES }}$}

\section{Shane Chaplin, Ph.D.}

Training Director, Psychologist

West Virginia University Carruth Center for Psychological and Psychiatric Services

390 Birch Street

Morgantown, WV, 26506

Telephone: 304-293-4431

Email: Shane.Chaplin@mail.wvu.edu

\section{Shannon Foster, M.S.}

Director

West Virginia University Office of Wellness and Health Promotion

390 Birch Street

Morgantown, WV, 26506

Telephone: 304-294-2355

Email: Shannon.Foster@mail.wvu.edu 


\section{Tandy McClung, Ed.D.}

Psychologist

West Virginia University Carruth Center for Psychological and Psychiatric Services 390 Birch Street

Morgantown, WV, 26506

Telephone: 304-293-4431

Email: Tandy.Mcclung@mail.wvu.edu 